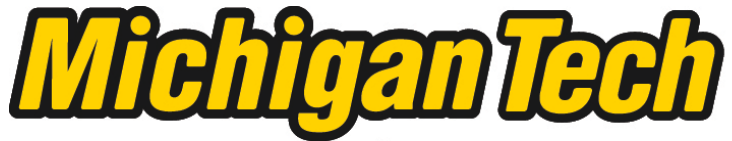 \\ Michigan Technological University Create the Future Digital Commons @ Michigan Tech
}

2013

\section{A DECOMPOSITION ANALYSIS OF BASE METAL PRICES: COMPARING THE EFFECT OF DETRENDING METHODS ON TREND IDENTIFICATION AND CYCLICAL COMPONENTS}

Mahmoodreza Modirroosta

Michigan Technological University

Follow this and additional works at: https://digitalcommons.mtu.edu/etds

Part of the Economics Commons

Copyright 2013 Mahmoodreza Modirroosta

Recommended Citation

Modirroosta, Mahmoodreza, "A DECOMPOSITION ANALYSIS OF BASE METAL PRICES: COMPARING THE EFFECT OF DETRENDING METHODS ON TREND IDENTIFICATION AND CYCLICAL COMPONENTS", Master's Thesis, Michigan Technological University, 2013.

https://doi.org/10.37099/mtu.dc.etds/674

Follow this and additional works at: https://digitalcommons.mtu.edu/etds

Part of the Economics Commons 


\title{
A DECOMPOSITION ANALYSIS OF BASE METAL PRICES: COMPARING THE EFFECT OF DETRENDING METHODS ON TREND IDENTIFICATION AND CYCLICAL COMPONENTS
}

\author{
By \\ Mahmoodreza Modirroosta \\ A THESIS \\ Submitted in partial fulfillment of the requirements for the degree of \\ MASTER OF SCIENCE \\ In Applied Natural Resource Economics \\ MICHIGAN TECHNOLOGICAL UNIVERSITY \\ 2013 \\ (C) Mahmoodreza Modirroosta
}


This thesis has been approved in partial fulfillment of the requirements for the Degree of MASTER OF SCIENCE in Applied Natural Resource Economics

School of Business and Economics

Thesis Advisor: Dr. Mark Roberts

Committee Member: $\quad$ Dr. Xavier de Castro Oliveira

Committee Member: Dr. Seyyedmohsen Azizi

School Dean: Dr. R. Eugene Klippel 


\section{Table of Contents}

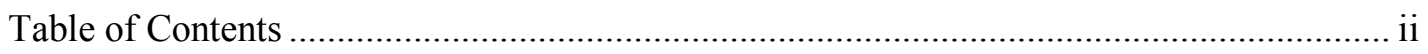

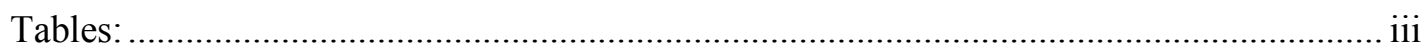

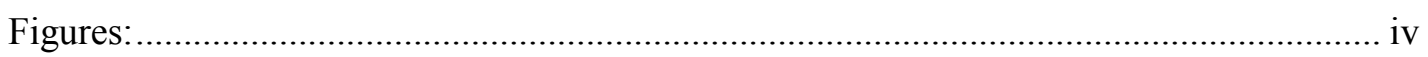

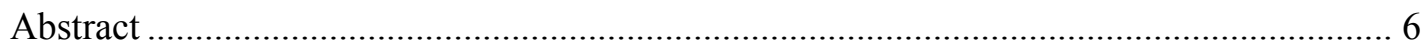

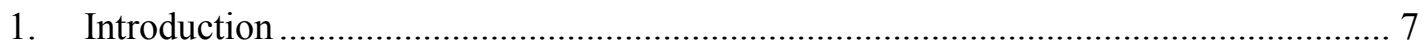

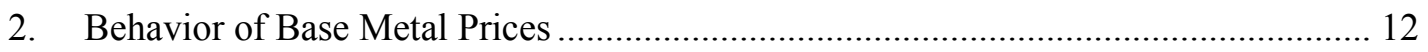

3. Literature review of long-term trend and cyclical behavior in mineral prices ............. 17

4. Detrending and filtering of base metal prices....................................................... 21

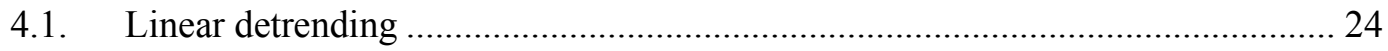

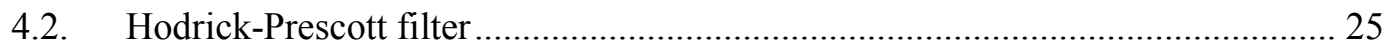

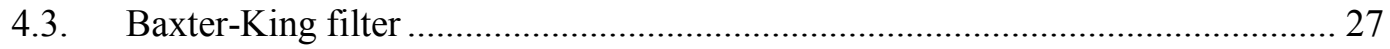

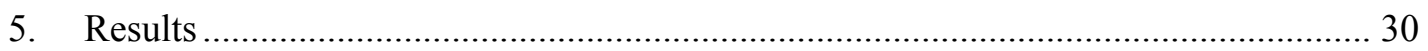

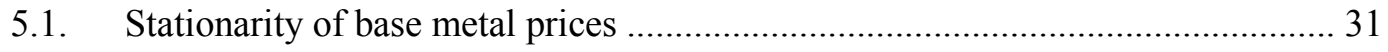

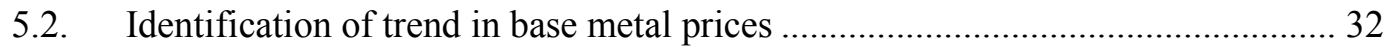

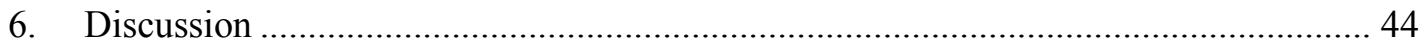

6.1. General properties of detrending methods .................................................. 46

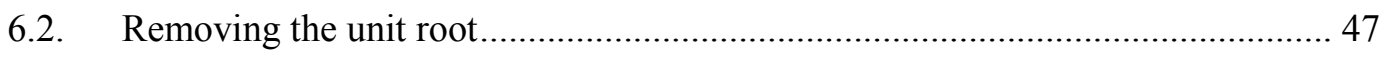

6.3. Correlations between the cyclical components …........................................... 48

6.4. Differences between the identified cycles in base metal prices ......................... 50

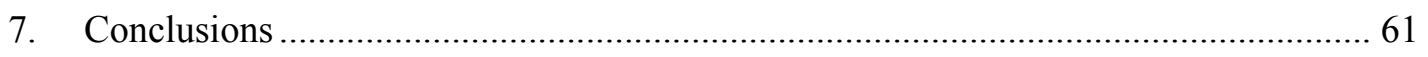

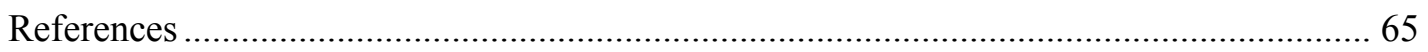




\section{Tables:}

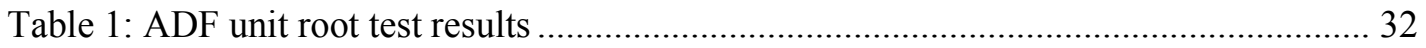

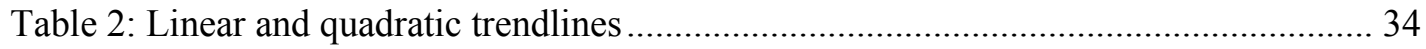

Table 3: The importance of trend component in different methods ................................... 43

Table 4: Unit root test of the cyclical components of different methods ............................ 47

Table 5: Correlation of the cyclical components of aluminum price using different methods

Table 6: Correlation of the cyclical components of copper price using different methods.. 48

Table 7: Correlation of the cyclical components of nickel price using different methods... 49

Table 8: Correlation of the cyclical components of lead price using different methods ...... 49

Table 9: Correlation of the cyclical components of tin price using different methods ........ 49

Table 10: Correlation of the cyclical components of zinc price using different methods .... 49

Table 11: Duration of phases in aluminum price using different methods ......................... 59

Table 12: Duration of phases in copper price using different methods..............................59

Table 13: Duration of phases in nickel price using different methods ................................ 60

Table 14: Duration of phases in lead price using different methods .................................... 60

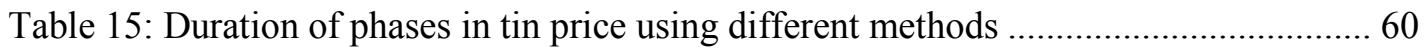

Table 16: Duration of phases in zinc price using different methods ................................... 60 


\section{Figures:}

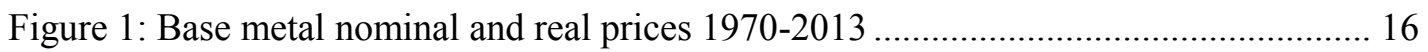

Figure 2: Frequency response function of a band pass filter............................................. 30

Figure 3: The frequency response function of Baxter-King filter ..................................... 36

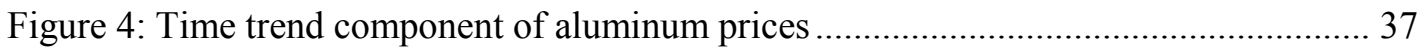

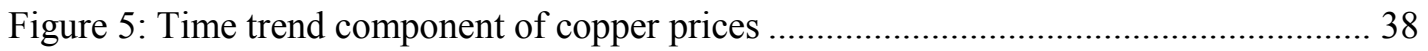

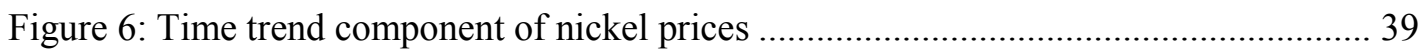

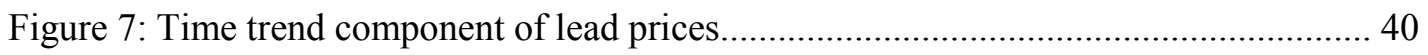

Figure 8: Time trend component of tin prices ............................................................. 41

Figure 9: Time trend component of zinc prices............................................................ 42

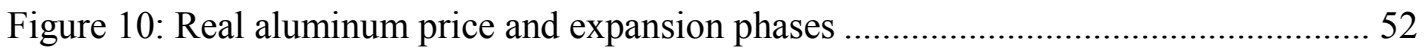

Figure 11: Real copper price and expansion phases........................................................ 53

Figure 12: Real nickel price and expansion phases ........................................................... 54

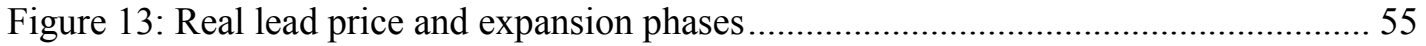

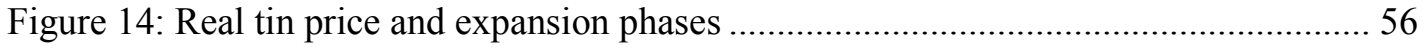

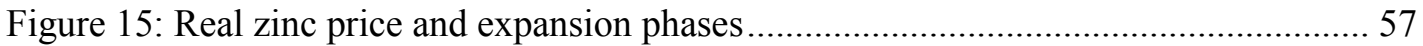




\begin{abstract}
This thesis analyzes the long-term trend behavior and cyclical components of real base metal prices. A decomposition approach is used to separate the real prices of base metals into a time trend and cyclical components. In this regard, linear and quadratic detrending methods along with Hodrick-Prescott and Baxter-King filters are applied to the base metal prices. Linear and quadratic trendlines are good estimates of the trend component and easy to interpret if the coefficients of estimated trends are significant and the coefficient of determination is relatively high. The HodrickPrescott and Baxter-King filters are good fits to the price series, but they affect the cyclical component. Loss of data points and altering the moments of the cyclical component are the disadvantages of filtering methods. On the other hand, the linear detrending methods are weak in removing unit roots in the series. This study shows that the choice of detrending method affects the cyclical component of base metal prices, and consequently the identification of cycles depends on the detrending method.
\end{abstract}




\section{Introduction}

Metal market analysis has been an important field of study in mineral economics and finance. Metal supply, demand, pricing and modeling has attracted great attention by academicians and researchers. Among the plentiful academic and empirical research which has been done over the past 30 years, modeling and forecasting of metal prices including base metals, precious metals, steel, minor metals and rare earth minerals has been attracting more attention than other aspects of the metals industries such as production, consumption, long-run availability, recycling and so on.

The importance of metal prices stems from the fact that price is the interface of all the other features of a metals market. Production decisions and the rate of production are highly dependent on metal prices. Companies will reduce their production rate or postpone new projects if the market price of the metal is not high enough, because the current metal price and expected future prices have strong effects on the profitability of extraction, the company's valuation and the evaluation of new projects to develop the production capacity or variation of the production rate. On the demand side, the choice of metals used in manufacturing a product is significantly determined by metal prices. A higher price for a metal will direct the industry users to search for other feasible substitutes. Therefore, long-term trends and fluctuations of metal prices are of great interest to producers and consumers of metals. 
Metal price is also considered an indicator of resource availability (Tilton 2003). The important advantages of price over other measures of resource availability include the accessibility and reliability of prices. As reserves of a metal become scarce, the price increases and motivates the development of new technologies. Furthermore, low grade and remote sources of the mineral become economically viable alternatives at higher prices.

This research is focused on non-ferrous base metal prices. The non-ferrous or base metals group encompasses industrially used metals like aluminum, copper, nickel, zinc, tin, and lead. This group of metals plays an important role in most national economies, and their prices have important impacts on the extraction, processing and manufacturing sectors (Watkins and McAleer 2004). Metals of this group are extensively traded on major commodity exchanges including the London Metal Exchange (LME), Commodity Exchange (COMEX) division of Chicago Mercantile Exchange (referred as CME Group Inc.), Shanghai Futures Exchange (SHFE) and most recently in Multi Commodity Exchange (MCX) in India. One major function of these exchanges is price discovery and the other, which is not the focus of this research, is hedging against price fluctuations. The LME prices are extensively used by different sectors and metal industry participants including mining, refining and smelting, manufacturing, recycling, and by traders and investors. As noted by Watkins and McAleer (2004), approximately 95\% of copper futures trades are 
executed on the LME and the remaining are on the COMEX and SHFE. Other regional markets handle spot trading of non-ferrous metals.

This research examines base metal prices through different aspects. It gives a broad view of spot prices in the long and medium-term. In this regard, base metal prices will be analyzed independently of other market variables such as supply, demand and inventories. Structural modeling of commodity prices considers the interactions between endogenous market variables such as price and quantity demanded with some exogenous variable such as industrial production and technological factors (Labys 2006). Therefore, the models in this research will examine the LME monthly prices of base metals which is the only one freely available and reliable with high frequency. Other data and statistics related to the base metals market such as futures and options prices, production from different sources, consumption, recycling and inventories are also available, but are not used in this research mainly due to low frequency and less availability. The other feature of this research is its monthly sampling frequency which is consistent with the majority of the econometric and statistical models of base metal prices (Watkins and McAleer 2004). This feature makes it possible to modify the data and use the results and findings of this study in accordance with other economic variables such as inflation and business cycles.

In this thesis decomposition analysis is used to study the long-term behavior of the base metal prices. In this regard, the real prices of base metals are decomposed into 
time trend and cyclical components. The decomposition analysis in this research is concentrated on two aspects of base metal prices, specifically: the effect of the detrending method on trend identification, and the impact of the detrending method on the cyclical components. Long-term and medium-term price trends and estimation of future prices are essential in the metals industry. This study is divided into two sections. In the first section, base metals prices are reviewed and analyzed to identify trends in the long term. Econometric methods are used to break down the base metal prices into time trend and cyclical components. The trend component of price refers to any long term upward or downward movements in the prices. In this regard, time series of price could be trendless which is indicated by a constant mean over the time span. In other words, the stationarity of base metal prices are examined by employing regular tests such as the Dickey-Fuller (Dickey and Fuller 1981) test. The results of this section are used to identify the best fitted trend in the series of base metal prices.

The second part of this study is devoted to the review of cyclical component of base metal prices. Visual inspection of base metal prices depicts some cycles; peaks and troughs are repeated with different durations and amplitudes. The first part of this section reviews the detrending approaches to extract the time trend component of a time series including linear or quadratic trends along with more sophisticated methods such as the Hodrick-Prescott (Hodrick and Prescott 1997) and the Baxter-King (Baxter and King 1999) filters. This part of the study presents the effects of deterending methods or filtering techniques on the cyclical component of base metal 
prices. In this regard several characteristics of filters are compared with respect to their ability to extract the cycles without any shift or alteration in duration of cycles, their power to detect the time trend component, and to eliminate unit roots (Baxter and King 1999).

In previously conducted research, one or several models have been specified and estimated for one type or a pool of commodities. By applying sophisticated methods, the trend component is identified in the time series of base metal prices more accurately, while the cyclical component may be affected by the choice of detrending method. There are different, and in some cases opposing theories, regarding trend identification in primary commodity prices such as: deterministic upward, downward, or U-shape trends. Regardless of the type or direction of the time trend component of a time series, the spectral analysis might be sensitive to the deterending method. Comparison of the cyclical component of each base metal series reveals the difference between deterending methods. However, determination of the most appropriate or optimal detrending method is of much interest, but this goal is not perused in this research.

This thesis is laid out in the following order. In the first section, the behavior of base metal prices is explained. A brief literature review of long-term trend and cyclical behavior of mineral prices is presented in section 3. Detrending and filtering methods including linear and quadratic detrending and the Hodrick-Prescott and Baxter-King 
filters are reviewed in the fourth section. The results of trend identification and the properties of detrending methods are presented in section 5. In this section, the Augmented Dickey-Fuller (ADF) test and the results of its application to base metal prices are illustrated. In the sixth part of this thesis, the effects of the detrending method on the cyclical component of base metal prices are discussed. And finally, the last section concludes this study.

\section{Behavior of Base Metal Prices}

The behavior of price is ever changing; sometimes in a fraction of minute, sometime in a day or it might remain pegged for a while. Price is the result of the interaction between supply and demand to balance the amount demanded with the quantity supplied of a good or service, so it is subject to alternation by changes in the factors affecting supply and demand or it may be distorted by external factors such as market structure or government policies. Prices are both cause and effect (Warren and Pearson 1933); changes in prices of commodities affect different groups of people, institutions and countries, while these groups may affect the prices at the same time.

Base metal prices including aluminum, copper, zinc, nickel, lead and tin are monitored globally. Vast applications of base metals in a variety of manufactured products have brought them to attention among producers, consumers and even investors. Considering the huge volume and the frequency of physical and financial instruments transacted on base metals, competitive and transparent markets give rise 
to available and reliable prices to the extent that base metal prices are considered as an economic indicator showing the situation of global economic activity.

As noted by Radetzki (2008) metal prices are alternatively determined in auctions, set in bilateral contracts or even dictated by small number of major producers or consumers depending on the size and trading activity of the market. In this classification for commodity price formation, transparency and availability of prices decrease with decreasing number of market participants and increasing market concentration. Recently, mainly due to declining concentration of production, more competitive conditions, and reduction of government intervention (Radetzki 2008) the price of metals have been determined, or more specifically discovered in metal exchanges, and other alternative trading is highly influenced by the exchanges' price. LME non-ferrous metal prices are considered to be a reliable reference for over-thecounter physical trading. Today, base metal prices that are discovered in LME and COMEX are disseminated all around the world and these prices are the basis of transactions in other the spot, futures or forward markets.

Having a competitive market is a plausible presumption for the majority of base metals because of the large number of market participants and high volume of trading either in the form of spot or derivatives all around the world. In 2011, for example, LME Copper contract was the second largest after the LME Aluminum contract by volume of 37.9 million lots traded. Given that a contract is 25 tones grade A copper 
cathodes, this is equivalent to 947.5 million tons of copper being traded in 2011 . Comparing the amount of traded contracts on the LME with the world total production of 19.8 million tons in 2011 indicates the high volume and significance of the LME copper price in this industry.

The long history of daily trading of base metals in major metal exchanges has made their prices available since the beginning of the 20th century. The monthly cash settlement price of base metals can be extracted from the London Metal Exchange. The availability of monthly prices from the Statistical Office of the United Nations Conference on Trade and Development (UNCTADSTAT) ${ }^{1}$ has determined the time span of this study from 1970:1 to 2013:7. This is the source of data for all six base metals including high grade aluminum, grade A copper electrolytic wire bars/cathodes, nickel, lead, special high grade zinc and tin. The data are not seasonally adjusted.

Real prices of base metals are reviewed over the long-term in this study. The monthly data on the US consumer price index (CPI) for all items less food and energy (1982$84=100)^{2}$ from U.S. Bureau of Labor Statistics is used as the deflator in this study. Since food and energy are more volatile than other goods, they are excluded to show long-term trends or significant changes in the overall value of money. Moreover, food

\footnotetext{
${ }^{1} \mathrm{http} / / /$ unctadstat.unctad.org/ReportFolders/reportFolders.aspx

${ }^{2} \mathrm{http}: / /$ www.bls.gov/cpi/\#data
} 
and energy prices are more subject to shocks than other goods and services (Lebow and Rudd 2006).

Figures and graphs may reveal some trends or cycles in the series, but further statistical analysis is required to identify any trends or cycles beyond personal biases or graphical distortions. However, visual inspection of price plots over time is the very first step in analyzing almost every time series. According to Labys (2006) the possibility that commodity market prices are stochastic gives rise to a large amount of risk and uncertainty to the process of market analysis and forecasting. A statistical analysis of prices helps to understand the behavior of prices and to develop econometrics models in order to construct proper models and forecast the future prices more accurately. Such quantitative approach decreases biased judgments in analyzing the behavior of price and helps to express forecasting in statistically sound models. 

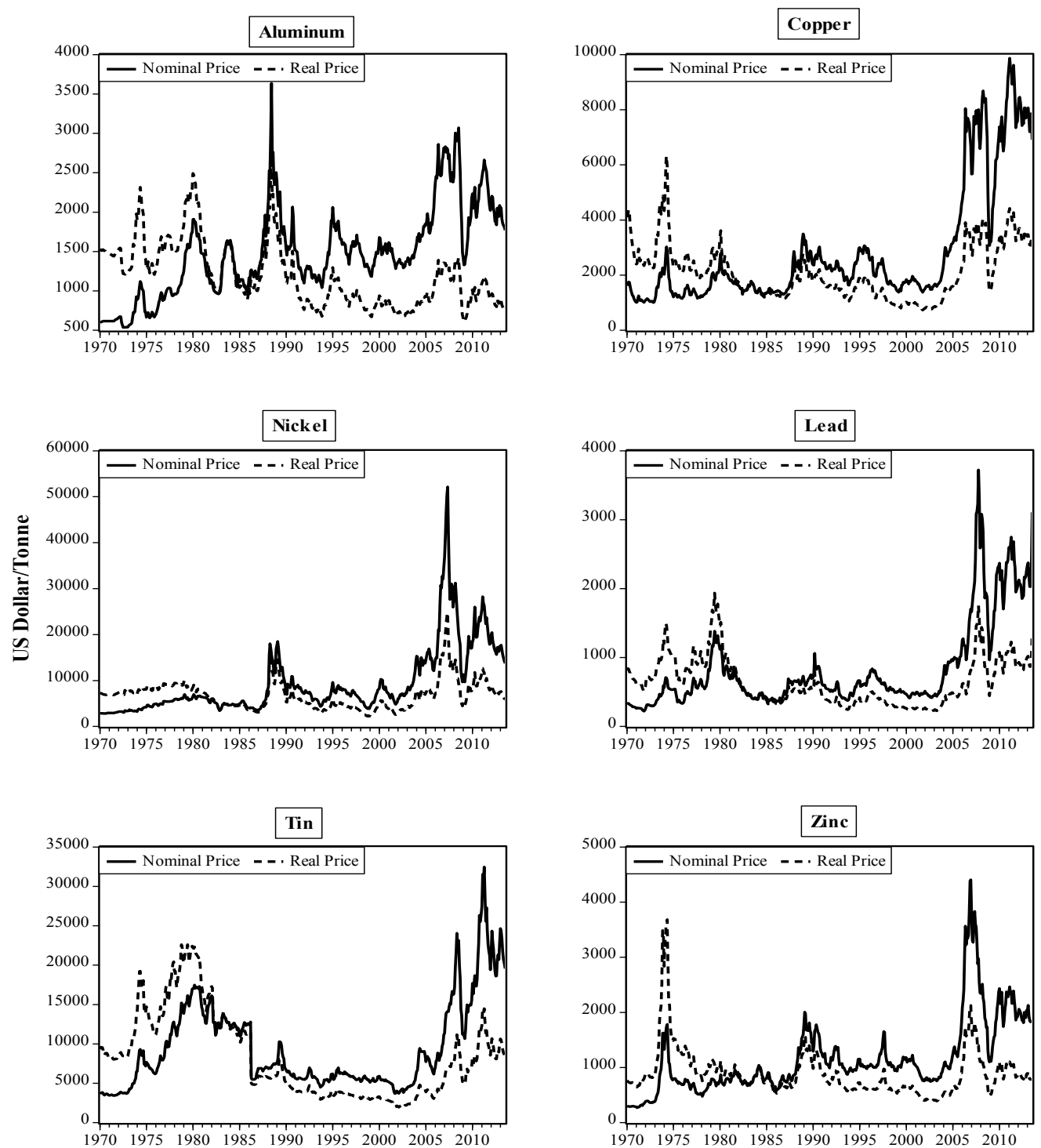

Figure 1: Base metal nominal and real prices $1970-2013^{3}$

${ }^{3}$ Nominal prices of metals have the same data source:

http://unctadstat.unctad.org/ReportFolders/reportFolders.aspx 
Figure 1 illustrates the nominal and real prices of base metals from January 1970 to August 2013. These are the univariate time series of nominal and real prices of each metal over time. Fluctuations are obvious in all the graphs along with slight downward trends in the real prices and modest accentuating trends in nominal prices. However, even though these metals belong to the same group, their prices demonstrate different behavior over this time span. Expansion or contraction of the time span may reveal different behavior in base metal prices, but with respect to the real prices of base metals, deflated current prices are at the same level now as they were in early 1970s except for aluminum. Visual observation of the graphs shows the same trends and fluctuations in the nickel, lead and zinc diagrams. The same behavior in the price of aluminum and copper is obvious except for the sharp spike in the aluminum price in the late 1980 s.

\section{Literature review of long-term trend and cyclical behavior in mineral prices}

One of the early studies in analyzing the behavior of mineral commodities was conducted by Potter and Christy (1962). They indicated that the real price of mineral commodities deflated by PPI dropped by $40 \%$ between 1870 and 1957 . They found many short term fluctuations over this period, but little alterations over the long term. They also showed that inspecting individual mineral commodities revealed the differences in trend of prices better than commodity indices for a group of minerals. 
In other research, Manthy and Potter (1978) indicated that real prices of natural resource commodities follow a linear trend which increase, decline or stay constant in the long term. Barnett and Morse (1963) studied mineral prices and showed that real mineral prices were fairly constant in the last quarter of the $19^{\text {th }}$ century. Lewis (1954) recommended that commodity prices probably do not exceed their production cost in the long term. Research conducted by Slade (1982) revealed that commodity prices had a U-shape pattern contrary to Hotelling's model which had suggested that non-renewable minerals real prices should follow an increasing path over time. Another important study related to identification of trends in the real prices of primary commodities was done by Prebisch and Singer (1950) and gave rise to a hypothesis that there had been a negative long-term trend in the prices of primary commodities. They believe this trend was probably going to continue into the future. Cuddington (1992) reviewed Prebisch-Singer Hypothesis in 26 primary commodity prices and showed that prices of 16 commodities were trendless, 5 commodities had positive and the remaining had downward trend between 1900 and 1983. He applied the unit root test to identify whether the commodity prices are trend stationary, that is, the presence of unit root cannot be rejected. The other study by Cuddington and Nülle (2013) has explained the long-term behavior of real mineral prices between 1900 to 2010. They used band pass filters to extract the time trend component of real mineral prices. They relaxed the assumption of constant upward or downward trend in the mineral prices and gave some flexibility to the time trend component to undergo gradual changes 
over time. They believe this feature allows the time trend to capture the changes in the mineral industry and shows the interactions between depletion, exploration, changes in technology and other influential factors to mineral commodity prices (Cuddington and Nülle 2013).

Comparing to the amount of research which has been done about the long-term trend in mineral prices, mineral price cycles have received less attentions (Labys 2006). However, cyclical behavior of macroeconomic indicators and duration of business cycles has been an attractive topic. The measurement of business cycles has been a challenging practice. There are plenty of methods to analyze the cyclical component of economic time series and to detect the cycles. One of the early methods to identify general business cycles is attributed to Burns and Mitchell (1946). Their procedure in cycles and turning points identification has been used extensively and became the NBER procedure in identifying business cycles. Bry and Boschan (1971) developed a procedure to search for the expansion and contraction in a series. Another seminal work in detecting cycles in economic time series is attributed to Harding and Pagan (2002). The majority of research about the cycles in commodity prices is about very long or super cycles. However, medium-term cycles of about 30 to 50 years have been studied recently (Blanchard, Nordhaus et al. 1997, Krugman, Dominquez et al. 1998, Solow 2000). In these studies band pass filters have been used in order to identify cycles in economic series. Labys, Lesourd et al. (1998) applied the common business cycle identification methods on some metal prices and employed time series methods 
to examine the significance of detected cycles. Average prices of some metals over 100 year were studied by Davutyan and Roberts (1994). The result of this study revealed that there is some degree of regularity in the phases and cycles of the price of the majority of studied metals. Roberts (2009) examined the cyclicality of fluctuations in metal prices. He tested duration dependence on phases and full cycles of 14 metals and showed there are some degree of cyclicality in metal prices. He also compared the duration of expansion and contraction phases and showed that contraction phase generally last longer than expansion phase in metal prices.

All the controversial works of business cycle identification are dependent on the practices adopted to extract the cyclical component of time series. Extraction of the cyclical component of time series is a complicated task in decomposition analysis because the residuals of detrending methods are composed of lower frequency cyclical component and higher frequency noises. Therefore, different decomposition methods provide different input for spectral analysis of time series. This feature leads to lack of a common agreement among researchers about an appropriate or optimal method to decompose time series. Canova (1998) believes that different detrending methods give rise to the estimation of different cyclical components. He does not argue that any of the detrending methods does a superior job in extracting the cyclical component than other methods. 
Much research has been done to model mineral commodity prices as summarized above. The results of these studies show that there are some obvious trends for a period of time that could be modeled mathematically. However, there is evidence that the behavior of mineral commodity prices vary over time. There are several theories behind these models that work appropriately over a period of time, but lose their reliability in the next period. Mainly due to many uncertainties in different aspects of mineral markets such as market structure, mineral resources, short term distortions (like wars or government policies) and many other factors postulating a robust theory which encompasses all perspectives and aspects of the whole industry or even a single commodity does not seem appropriate. The factors affecting the mineral markets and their strength are changing over time and this makes the analysis of mineral markets very complicated. Although much research has been conducted related to modelling and forecasting of mineral prices, there are still more opportunities to apply new theories and utilize new methods to achieve the goal of modelling primary commodity prices.

\section{Detrending and filtering of base metal prices}

In time series analysis, looking for trend and cyclical components of economic data has attracted the attention of economists. Growth theory and long term availability of primary commodities are significant examples of the use of trend analysis of economic data. On the other hand, fluctuations of macroeconomic indicators and 
frequencies of business cycles is an example of using spectral analysis to find hidden frequencies in time series data. The time series analysis of economic data is important for analyzing different theories. For instance, there are three different theories about the long term trends in primary commodity prices and some of them are in opposition to others. An upward trend (Hotelling 1931), a downward trend (Prebisch and Singer 1950) or a U shape trend (Slade 1982) are the examples of deterministic trend recognition in the prices of primary commodities. On the other hand, spectral analysis of economic data is of importance to policy making. It is important to distinguish between a change in economic data that is a shift in trend or just a transitory movement associated with the cyclical behavior of data (Christiano and Fitzgerald 2003).

Cyclical behavior is another feature of commodity prices. This feature of commodity prices has also attracted attention from academicians and researchers. Cyclical patterns in time series of commodity prices may seem apparent when looking at the plot of prices over time, but finding regular and symmetric or asymmetric cycles is a cumbersome task to accomplish. Analyzing time series in order to find the cyclical patterns is the subject of spectral or frequency domain analysis. In this step, a detrended stationary time series is decomposed into the sum of various cycles with different frequencies and amplitudes (Christiano and Fitzgerald 2003). In spectral analysis, the existence of possible cycles with unknown frequencies is found from the series. 
There are plenty of methods to decompose a time series into trends and cycles. These methods include moving averages, differencing, detrending by extracting linear or quadratic trend, Hodrick-Prescott (HP) filter and Baxter-King (BK) filter. The time trend component could be defined as low frequency fluctuations of time series. Time trend component of time series should be extracted prior to the use of spectral analysis to look for hidden cycles. Another possible approach to detrend a series is filtering. Filters decompose the original series into low frequency component referred as the time trend and a higher frequency component referred as cyclical component. A filter provides a tool to separate components of a series with different frequencies. In other words, filters leave frequencies within a specific band and removes other frequencies outside a given band (Christiano and Fitzgerald 2003). Filters are divided into three subgroups: low pass filters, high pass filters and band pass filters. Low pass filters leave low frequencies and eliminate high frequencies. By using a low pass filter, short term fluctuations are removed from the series and the result contains the long term trend. A moving average is a filter that leaves low frequencies and reduces the significance of high frequency components and creates a smooth series. In other words, the residuals of a low pass filter contain high frequency components. On the opposite side, high pass filters leave high frequencies and eliminate low frequencies. In other words, the residuals of a high pass filter contain low frequency components. Consequently, a band pass filter could be set up in a way that leaves desired frequencies and removes undesired frequencies into residuals. 
As mentioned above, band pass filters provide a tool to decompose a time series into specified frequencies (Cuddington and Nülle 2013). Low pass filters are generally used to analyze the long term trend in time series by eliminating short term fluctuations in economic data. The advantage of using low pass filters in reviewing long term trends in mineral prices is that it does not assume a constant long term trend over time (Cuddington and Nülle 2013). Elimination of this assumption is plausible because there are different models regarding to the existence and direction of a long term trend in mineral prices. If band pass filters are utilized repeatedly on base metal prices, a combination of cyclical components with specified frequencies can be extracted from the series of prices. In this regard, the Hodrick-Prescott filter (Hodrick and Prescott 1997) and Baxter-King filter (Baxter and King 1999) are applied to base metal prices to extract the time trend and cyclical components. The cycle periods of cyclical component are defined according to the characteristics of each metal series over the time span from 1970 to 2013.

\subsection{Linear detrending}

Linear detrending is one of the most common practices in trend identification. In this approach a straight line or a polynomial is fitted to the series. The implementation of linear detrending method is based on the OLS regression on time or a quadratic function. A Quadratic trendline may result in a better fit depending on the characteristics of the series. In trend stationary (TS) time series, the time trend of the 
series could be modeled as $p_{t}=\beta_{1}+\beta_{2} *$ time $+e_{t}$, where $p_{t}$ is the real price of base metal (Cuddington 1992). Another possible alternative approach to detrend nonstationary or stationary series is curve fitting. In a quadratic curve the time trend of the series is modeled as $p_{t}=\beta_{1}+\beta_{2} *$ time $+\beta_{3} *$ time $^{2}+e_{t}$.

Higher order polynomials may result in a better fit, while they can have some effects on the cyclical component of time series. Other mathematical functions such as exponential or logarithmic functions can also give a good fit to the series, but these functions are only able to give a good fit in a limited interval and show unexpected behavior beyond it.

\subsection{Hodrick-Prescott filter}

Hodrick-Prescott (HP) filter is a tool to decompose a time series into a growth or trend component and a cyclical component. Hodrick and Prescott (1997) proposed this procedure to break down a time series into a slowly changing growth or trend component and a cyclical component. The main purpose of using this procedure was to illustrate cyclical fluctuations in economic variables. They hypothesized economic variables are repeatedly fluctuating around their long term trend. In their approach, the trend component of an economic time series varies smoothly over time. They estimated the trend component and under the assumption of additive series, the cyclical component is calculated by subtracting the trend from the observed series. 
Given time series, such as base metal prices $\left(p_{t}\right)$, is comprised of the growth $\left(g_{t}\right)$ and cyclical $\left(c_{t}\right)$ componets.

$$
p_{t}=g_{t}+c_{t} \quad \text { for } \quad t=1,2,3, \ldots \ldots . T
$$

They developed a model to estimate the growth component

$$
\min _{\left\{g_{t}\right\}_{t=1}^{T}}\left\{\sum_{t=1}^{T}\left(p_{t}-g_{t}\right)^{2}+\lambda \sum_{t=1}^{T}\left[\left(g_{t}-g_{t-1}\right)-\left(g_{t-1}-g_{t-2}\right)\right]^{2}\right\}
$$

Where $p_{t}$, is the observed series or the real base metal prices, and $c_{t}=p_{t}-g_{t}$ denotes the cyclical component and $\lambda$ is the parameter which determines the smoothness of the trend component. As $\lambda$ approaches larger values, the estimated trend component is getting closer to the estimated coefficient of ordinary least square (OLS) of linear time trend (Hodrick and Prescott 1997). This is the time coefficient OLS regression for a stationary time series. In Hodrick-Prescott filtering, there is a trade-off between minimizing the cyclical component and the trend component. There is a penalty for the cyclical component of a series if the first term in the equation (2) is minimized. On the other hand, minimizing the second part penalizes the variation rate of the trend component (Hodrick and Prescott 1997). The value of $\lambda=1,600$ for quarterly data has been recommended by Hodrick and Prescott (1997). Ravn and Uhlig (2002) suggest to adjust $\lambda=129,600$ when working with monthly data. 


\subsection{Baxter-King filter}

Baxter and King (1999) developed a procedure to identify business cycles by applying a band pass filter to produce a stationary series. The Baxter-King filter is a technique mainly used to study the business cycles by applying a specific moving average according to the characteristics of the business cycle. The Baxter-King filter is usually used to extract the cyclical component of an economic time series data between specified periods. It is a linear filter that removes a two sided moving average out of the series and passes the cycles in a defined upper and lower cycle periods. The upper and lower range of cycles is set according to how long a cycle lasts. For example, it is widely believed that the business cycles endure between 1.5 to 8 years in an economy, so the lower and upper limit of the Baxter-King filter should be defined according to 6 and 32 if quarterly data is available or 18 to 96 for monthly data (Baxter and King 1999). Consequently, the filter removes components that are lower and higher than specified frequencies and passes the cyclical component of the series between the defined periods. In applying this filter on other economic data, the characteristics of the data should be taken into account. This filter does seem useful to apply to non-stationary time series with a stochastic time trend, because the stochastic time trend is removed by a two-side moving average and the remaining part would be stationary.

The two-sided moving average of Baxter-King creates a new series as: 


$$
p_{t}^{*}=\sum_{k=-K}^{K} a_{k} p_{t-k}
$$

Where $p_{t}$ is the real prices and $a_{k} \mathrm{~s}$ are the weights of the moving average. In the case of symmetric moving average the sum of weights equals to zero and the passed time series would be stationary. This feature makes the Baxter-King filter applicable to non-stationary economic data. $\mathrm{K}$ is the maximum lead and lag length or truncation. Applying this moving average to the series will result in a stationary time series with zero mean

$$
p_{t}=\int_{-\pi}^{\pi} \xi(\omega) d \omega
$$

Where, $\xi(\omega)$ is the cyclical or periodic component of the series with $\omega$ frequency. So, the filtered series could be written as

$$
p_{t}^{*}=\int_{-\pi}^{\pi} \alpha(\omega) \xi(\omega) d \omega
$$

In which $\alpha(\omega)=\sum_{k=-K}^{K} \alpha_{k} \exp (-i w k)$ is the frequency response of the filter. The frequency response shows the extent that $p_{t}^{*}$ responds to $p_{t}$ at $\omega$ frequency with respect to the $\alpha(\omega)$ which is the weight of random periodic component of $\xi(\omega)$ (Baxter and King 1999). It is worth noting that at zero frequency, the weight of the periodic component is zero. The cyclical component of BK filter is

$$
c_{t}=\sum_{j=-K}^{K} b_{j} p_{t-j}
$$


Where $b_{j}$ are the weights that could be found the inverse Fourier transform of the frequency response function as

$$
b_{j}=\frac{1}{2 \pi} \int_{-\pi}^{\pi} \alpha(\omega) \exp (i w j) d \omega(7)
$$

In an ideal filter, $b_{j}$ are $b_{0}=\underline{\omega} / \pi$ and $b_{k}=\sin (k \underline{\omega}) / k \pi$ for $K=1,2, \ldots$

The other important factor in implementing a Baxter-King method on economic data is the is the lag length $K$. Baxter and King believe that by increasing $K$ the performance of the filter is also increased, but the loss of $2 \mathrm{~K}$ observation has a negative effect on the performance of the filter. In the choice of $K$, leakage, compression and exacerbation should be taken into account. Leakage refers to the state that the filter passes some frequencies that are not supposed to pass through the filter. Truncation of a filter can also compress some frequencies (Baxter and King 1999). Finally, a frequency response of more than one is defined as exacerbation which shows the relative significance of the cyclical component in the range of upper and limit cycle periods. With increasing $K$, these problems are diminishing the frequency response function. Figure 2 depicts leakage, exacerbation and compression of a band pass (BK filter) filter. 


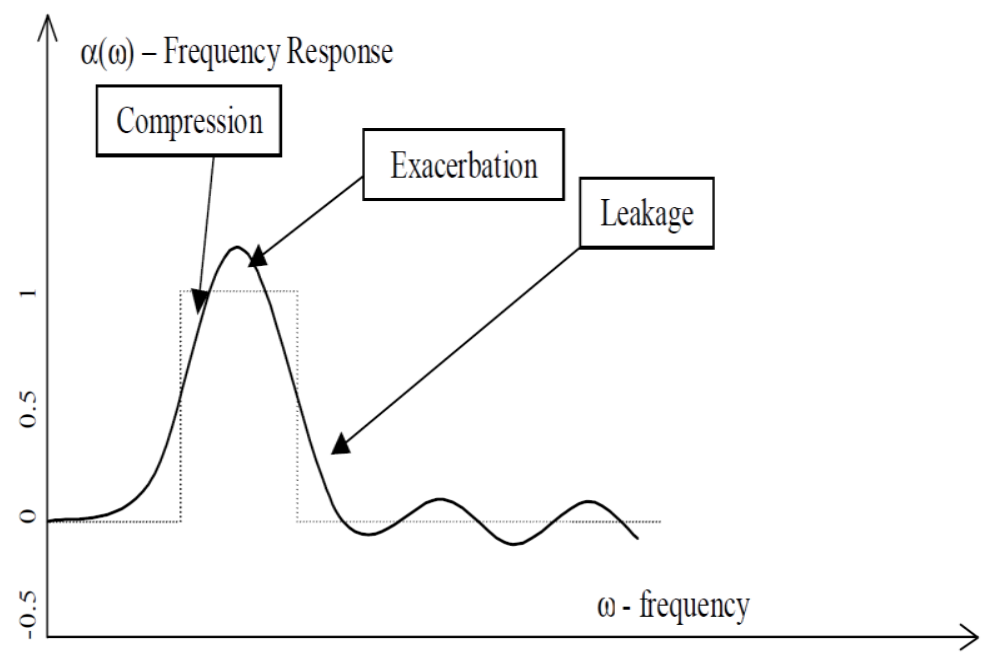

Figure 2: Frequency response function of a band pass filter

The dotted line shows the ideal band pass filter between the upper and lower limit frequencies. The solid line displays the frequency response function. This is a graphical way to choose the upper and lower frequencies which has the least leakage, exacerbation and compression problems.

\section{Results}

One of the most important features of commodity prices is the identification of trends in the long-term. Base metal prices fluctuate like other commodity prices. This fluctuation may be trendless or happen around an upward or a downward deterministic trend. Identification of trends in mineral prices in the long-term is of importance mainly to know about long-term availability of resources and evaluation 
of mineral projects. Detecting a general direction or a break in the trend of a price for a commodity or any class of assets is generally complicated. However, upward trends, downward trends and breaking points might seem obvious in a graphical display of prices, but these might be spurious and statistically invalid. Identification of authentic trends and structural breaks by using econometric modeling and statistical reasoning have been developed by several researchers. In the meantime, market practitioners and chartists have been using their own analytical tools such as trendlines and channels to detect different types of trends. This section presents the application of detrending and filtering methods to separate base metal prices into time trend and cyclical components.

\subsection{Stationarity of base metal prices}

The time coefficient of trend stationary series of prices are appropriate to assess the existence of deterministic trend ${ }^{4}$. Usually, the traditional Augmented Dickey-Fuller (ADF) test is used to test for the existence of unit root in time series. The first step to test for the presence of a unit root in a base metal price series is to apply the ADF test based on the following model:

$$
\Delta p_{t}=\beta_{1}+\beta_{2} \text { time }+\alpha p_{t-1}+\sum_{i=1}^{k} c_{i} \Delta p_{t-i}+e_{t}(8)
$$

\footnotetext{
${ }^{4}$ Cuddington (1992) regressed an ARMA model on the logarithm of the commodity price to study the time trend component in non-stationary series.
} 
To test for the presence of a unit root, both intercept and trend are included in the $\mathrm{ADF}$ test equation. Lag lengths were automatically selected based on Akaike Information Criteria (AIC) with the maximum lag length of 10 . Table 1 shows the results of applying the ADF test on the real base metal prices.

Table 1: ADF unit root test results

\begin{tabular}{lcccc}
\hline & \multicolumn{2}{c}{ Level } & \multicolumn{2}{c}{ 1st difference } \\
\hline & $\begin{array}{c}\text { ADF } \\
\text { statistic }\end{array}$ & Prob $\dagger$ & \multicolumn{1}{c}{$\begin{array}{c}\text { ADF } \\
\text { statistic }\end{array}$} & Prob $\dagger$ \\
\hline Aluminum & -4.01 & $0.008^{*}$ & - & - \\
\hline Copper & -2.81 & 0.193 & -6.77 & $0^{*}$ \\
\hline Nickel & -3.06 & 0.115 & -13.03 & $0^{*}$ \\
\hline Lead & -1.41 & 0.855 & -6.69 & $0^{*}$ \\
\hline Tin & -1.82 & 0.691 & -18.59 & $0^{*}$ \\
\hline Zinc & -4.97 & $0.000^{*}$ & - & - \\
\hline
\end{tabular}

$\dagger$ Probabilities are based on the MacKinnon one-sided p-values: 1\% (-3.9758)*, 5\% (-3.4185) **, $10 \%(-3.1317) * * *$

Based on the ADF test, the real prices of aluminum and zinc are stationary at $1 \%$ level of significance, respectively. For the remaining base metals, the presence of unit roots in the prices are not rejected. The results of applying ADF test on base metal prices indicate that real prices of copper, nickel, lead and tin are difference stationary, without considering the effect of possible breaks in the series of base metal prices.

\subsection{Identification of trend in base metal prices}

In this section, long-term trends are identified in the time series of base metal prices. Accurate estimation of trend components in the series of prices is of importance 
because the cyclical components of a price series is based on the identification of trends (Cuddington 1992). In a stationary series, a linear trend is a good estimation of the long-term trend of base metal prices. A quadratic trend line is fitted on the real prices of non-stationary base metal prices. The growth component of HP filter and the moving average of BK filter also show the time trend component of base metal prices. Since real prices of aluminum and zinc are stationary (Table 1), a linear trendline is a good estimate of time trend component. For the remaining base metals, the presence of unit roots in the real prices are not rejected (Table 1), so a quadratic trendline, the growth component of HP filter or the moving average of BK filter are tested to estimate time trend component. Differencing the non-stationary series creates a stationary series, but since the time trend component is also removed it is not practical in time trend identification.

Table 2 contains the result of linear and quadratic regression coefficients to identify the time trend component of base metal prices. The result shows that the time coefficients of linear trendlines are significant at $1 \%$ level in the series of aluminum, tin and zinc prices. 
Table 2: Linear and quadratic trendlines

\begin{tabular}{|c|c|c|c|c|c|c|c|}
\hline & \multicolumn{3}{|c|}{ Aluminum } & & \multicolumn{3}{|c|}{ Copper } \\
\hline & \multirow{2}{*}{$\begin{array}{c}\text { Linear } \\
\text { time }\end{array}$} & \multicolumn{2}{|c|}{ Quadratic } & & \multirow{2}{*}{$\begin{array}{c}\text { Linear } \\
\text { time }\end{array}$} & \multicolumn{2}{|c|}{ Quadratic } \\
\hline & & time & $\operatorname{Time}^{\wedge} 2$ & & & time & Time $^{\wedge} 2$ \\
\hline Coeff & -1.674 & -3.082 & 0.003 & Coeff. & -0.440 & -18.853 & 0.035 \\
\hline t Stat & -18.033 & -8.403 & 3.965 & t Stat & -1.529 & -23.575 & 23.777 \\
\hline P-value & 0.000 & 0.000 & 0.000 & P-value & 0.127 & 0.000 & 0.000 \\
\hline Adj. $\mathbf{R}^{2}$ & 0.383 & \multicolumn{2}{|c|}{0.400} & Adj. $\mathbf{R}^{2}$ & 0.003 & \multicolumn{2}{|c|}{0.521} \\
\hline & \multicolumn{3}{|c|}{ Nickel } & & \multicolumn{3}{|c|}{ Lead } \\
\hline & Linear & \multicolumn{2}{|c|}{ Quadratic } & & Linear & \multicolumn{2}{|c|}{ Quadratic } \\
\hline & time & time & Time $^{\wedge} 2$ & & time & time & Time $e^{\wedge}$ \\
\hline Coeff & 1.208 & -33.312 & 0.066 & Coeff & -0.390 & -5.362 & 0.009 \\
\hline t Stat & 1.324 & -10.075 & 10.781 & t Stat & -3.946 & -16.459 & 15.762 \\
\hline P-value & 0.186 & 0.000 & 0.000 & P-value & 0.000 & 0.000 & 0.000 \\
\hline Adj. $R^{2}$ & 0.001 & \multicolumn{2}{|c|}{0.182} & Adj. $R^{2}$ & 0.027 & \multicolumn{2}{|c|}{0.340} \\
\hline & \multicolumn{3}{|c|}{ Tin } & & \multicolumn{3}{|c|}{ Zinc } \\
\hline & Linear & \multicolumn{2}{|c|}{ Quadratic } & & Linear & \multicolumn{2}{|c|}{ Quadratic } \\
\hline & time & time & $\operatorname{Time}^{\wedge} 2$ & & time & time & Time $e^{\wedge}$ \\
\hline Coeff & -19.604 & -62.502 & 0.082 & Coeff & -0.786 & -4.037 & 0.006 \\
\hline t Stat & -14.936 & -12.774 & 9.054 & t Stat & -6.288 & -8.427 & 7.009 \\
\hline P-value & 0.000 & 0.000 & 0.000 & P-value & 0.000 & 0.000 & 0.000 \\
\hline Adj. $\mathbf{R}^{2}$ & 0.298 & \multicolumn{2}{|c|}{0.393} & Adj. R $^{2}$ & 0.069 & \multicolumn{2}{|c|}{0.148} \\
\hline
\end{tabular}

The quadratic time and time ${ }^{2}$ coefficients are also significant for all base metal prices. Along with the significance of the time coefficients, the goodness of fit should also be taken into consideration. For example, the time coefficients of linear and quadratic trendlines in zinc price are statistically significant. In these cases, relatively low $\mathrm{R}^{2}$ indicate that the time trend componets do not follow a downward or U-shape patterns. In order to determine the trend component of series, linear and quadratic trendlines 
should be taken into consideration along with the growth component of the HP filter and the moving average of the BK filter.

In order to apply the HP filter to base metal prices, the smoothing factor is set to 129,600 . This is based on the Ravn and Uhlig (2002) recommendation when working with monthly data ${ }^{5}$. Using the monthly prices of base metals, different upper and lower cycle periods and truncation lags were tested to find the optimal frequency response function. In this regard, minimizing the leakage, exacerbation and compression effect was taken into consideration. For the purpose of BK filtering of base metals, the truncation lag is $K=20$ and low and high limits of cycle periods are 12 and 40 months, respectively. Figure 3 displays the frequency response function of Baxter-King filter for base metal prices.

${ }^{5}$ There are other options for monthly data $(\lambda=14400,86400)$ 


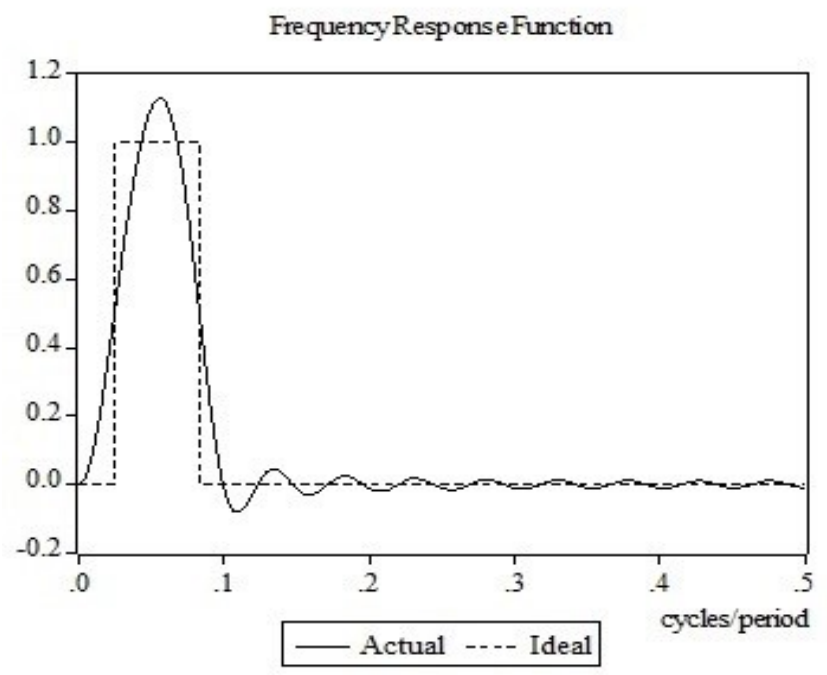

Figure 3: The frequency response function of Baxter-King filter

Figures 4-9 illustrate the time trend component of real base metal prices. In each diagram, the upper left is the real price of metal. The second graph shows the linear trend and the lower left graph depicts quadratic trendline. The upper right graph shows the growth component of the HP filter and the lower right graph displays the moving average of the BK filter. 

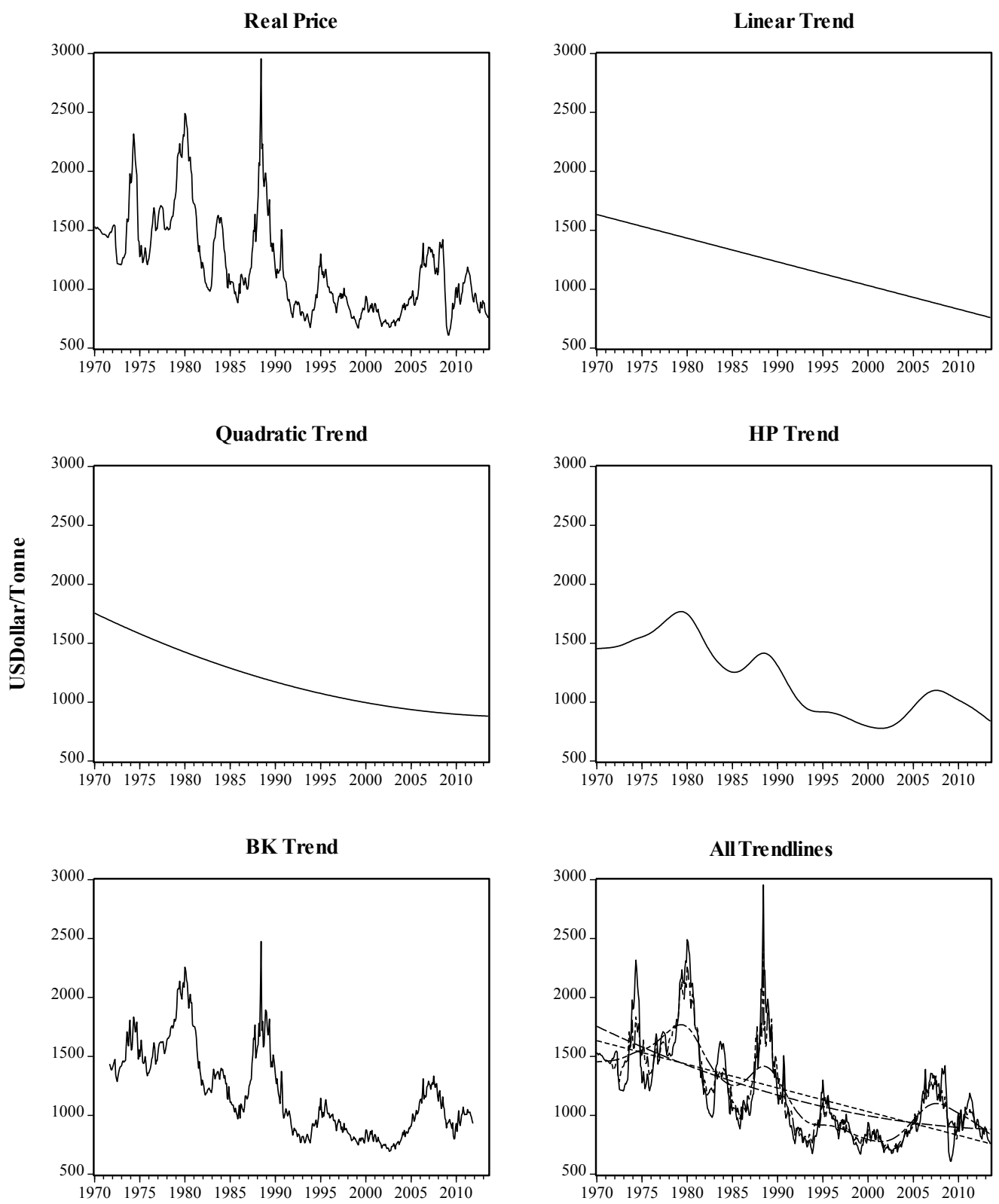

Figure 4: Time trend component of aluminum prices 

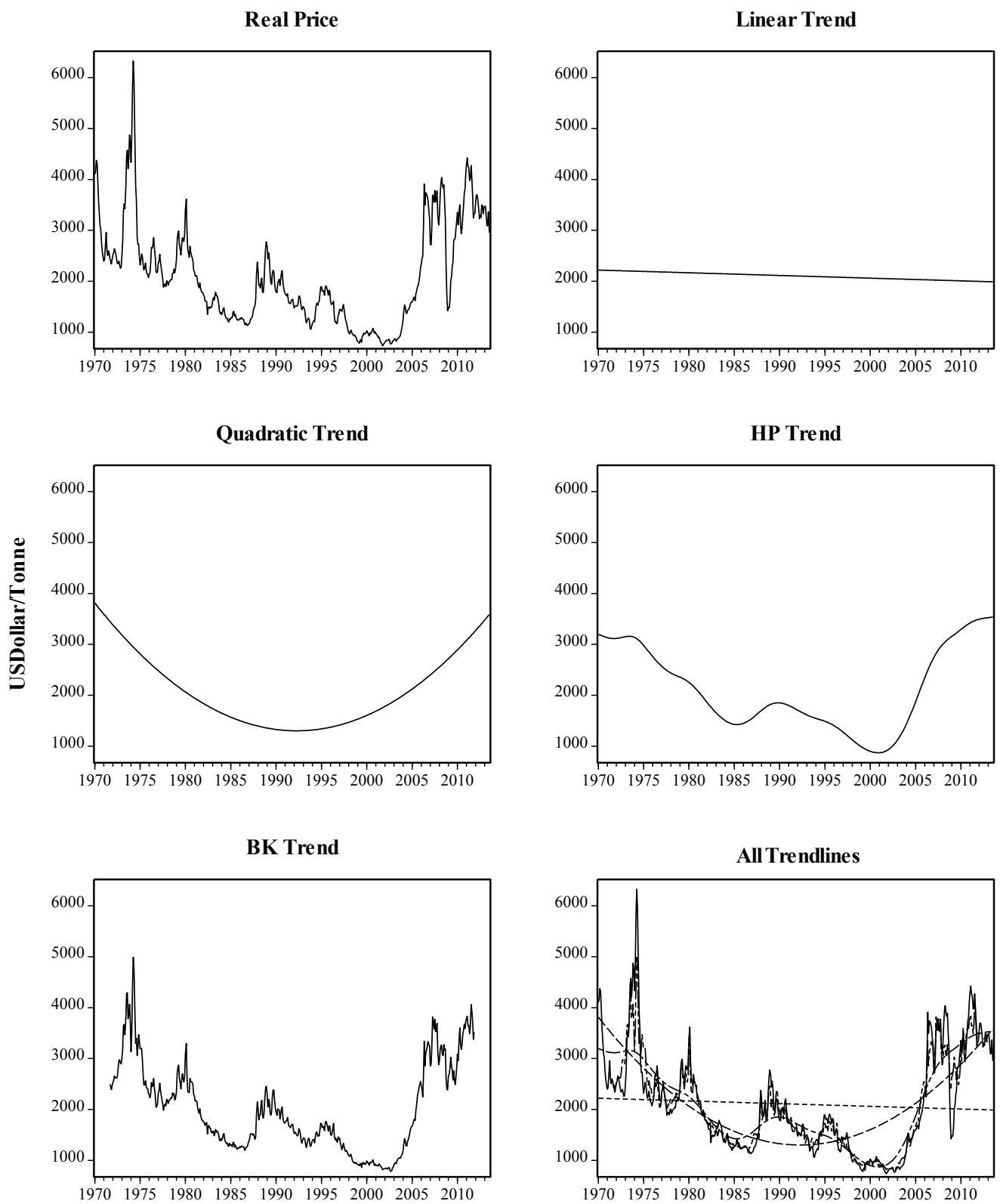

Figure 5: Time trend component of copper prices 

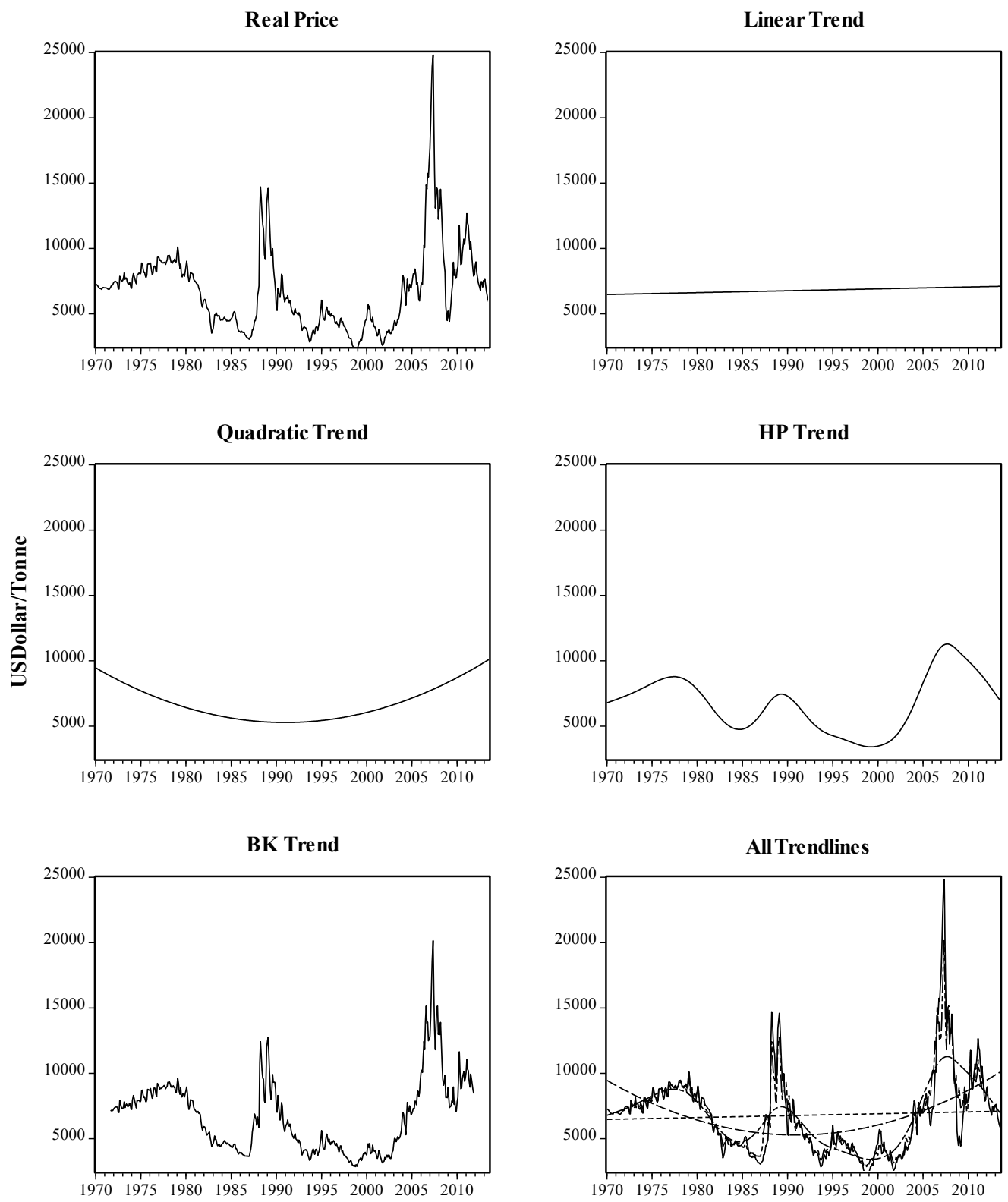

Figure 6: Time trend component of nickel prices 


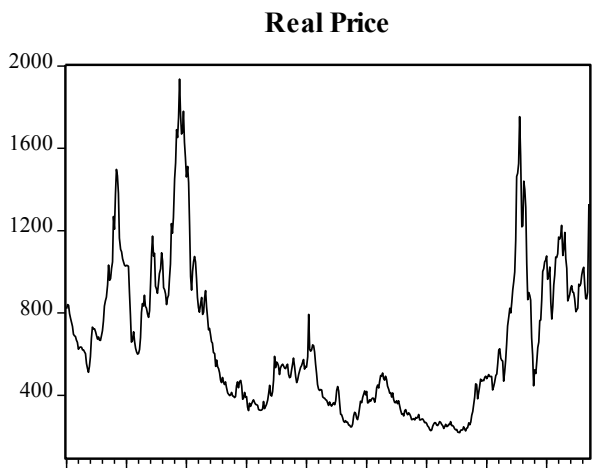

$\begin{array}{llllllllll}1970 & 1975 & 1980 & 1985 & 1990 & 1995 & 2000 & 2005 & 2010\end{array}$
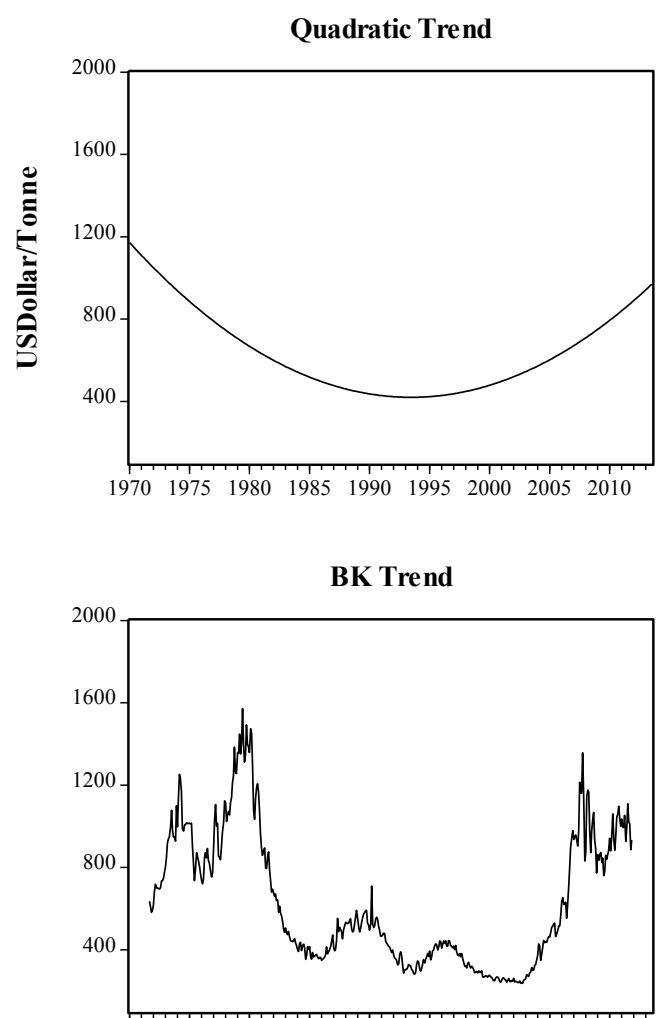

$\begin{array}{lllllllll}1970 & 1975 & 1980 & 1985 & 1990 & 1995 & 2000 & 2005 & 2010\end{array}$

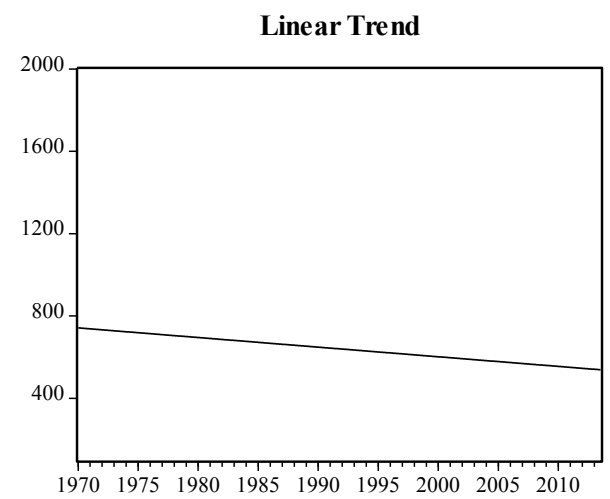

HP Trend

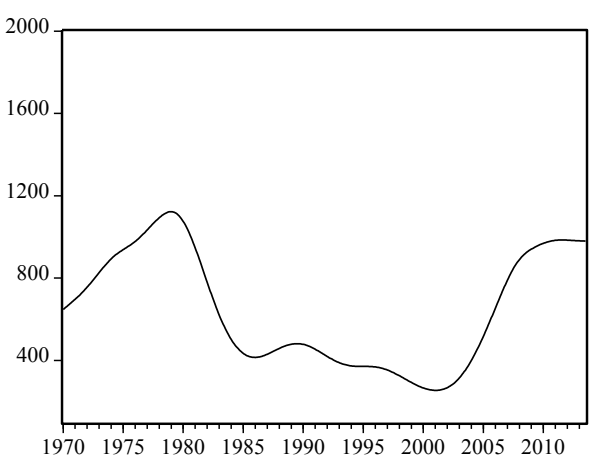

All Trendlines

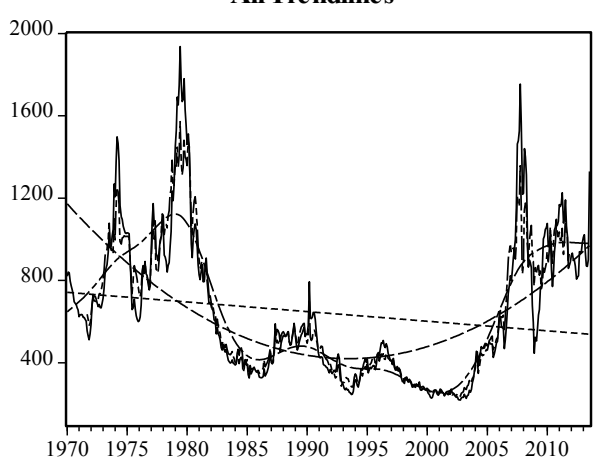

Figure 7: Time trend component of lead prices 

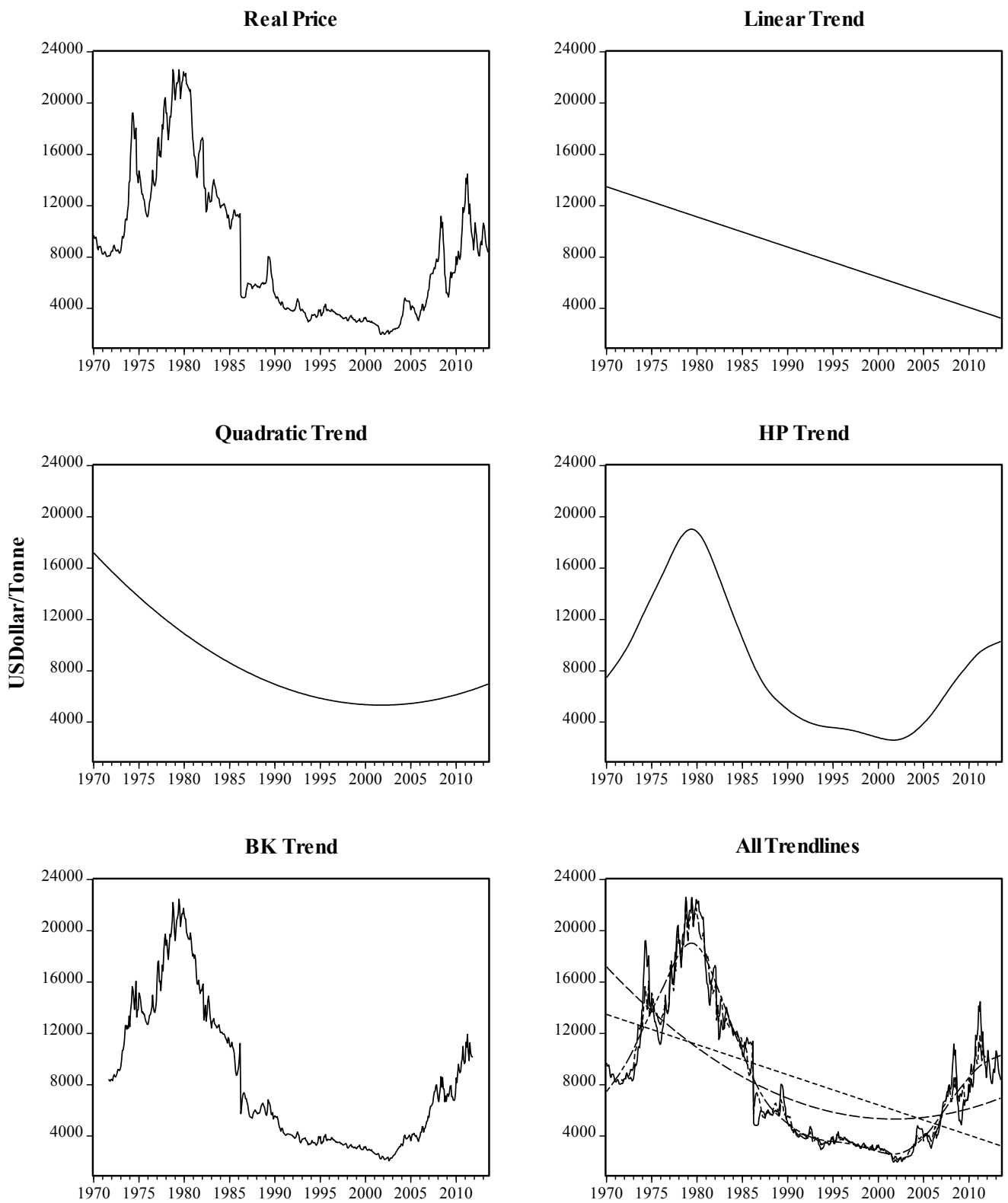

Figure 8: Time trend component of tin prices 

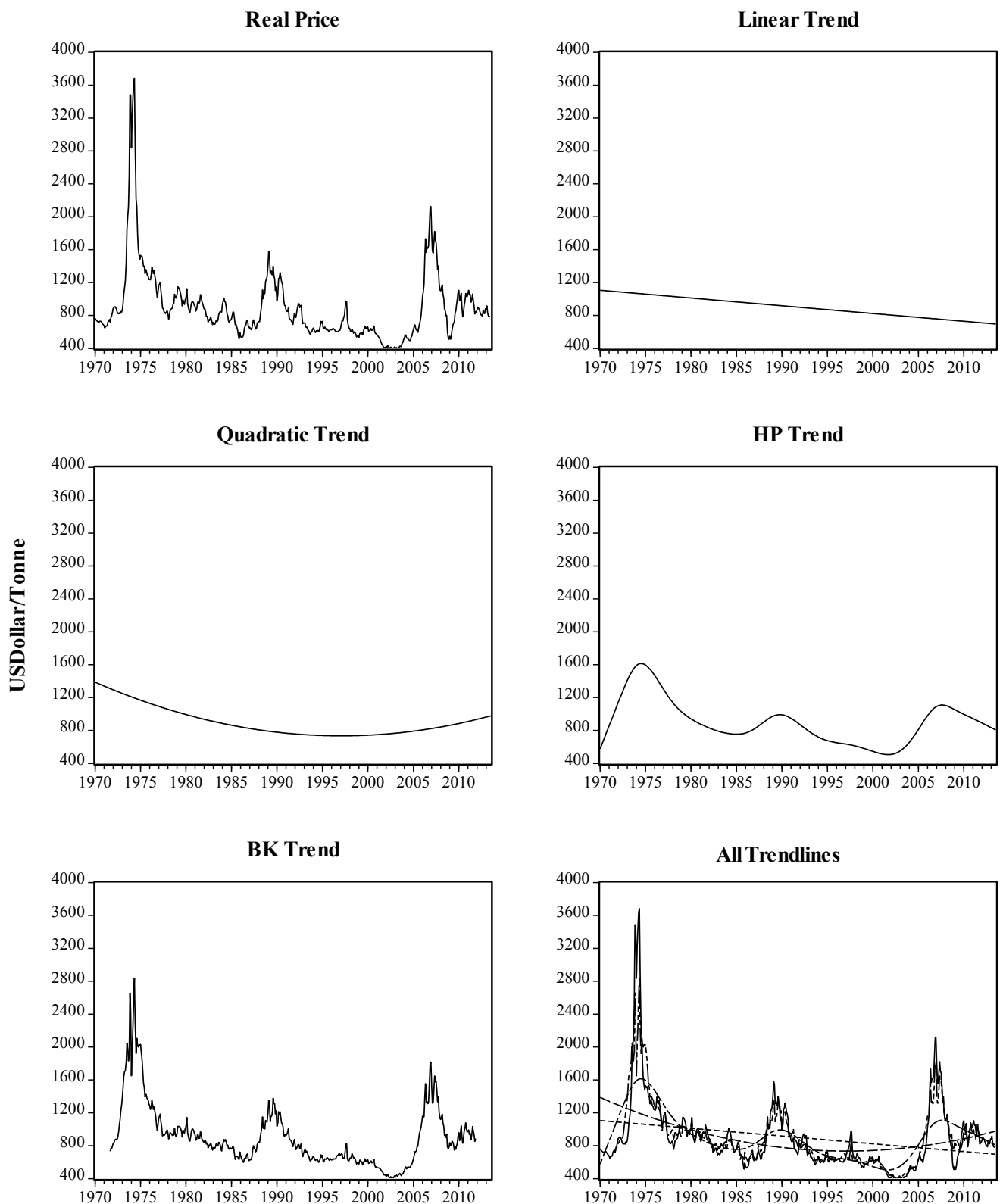

Figure 9: Time trend component of zinc prices 
The goodness of fitness could be captured by observing the trendlines and residuals which contains the cyclical component, it can be measured by dividing the variance of trendline fitted on the series by the variance of observations:

$$
R^{2}=1-\frac{\operatorname{Var}\left(c_{t}\right)}{\operatorname{Var}\left(p_{t}\right)}
$$

Where $\operatorname{Var}\left(p_{t}\right)$ is the variance of observed prices of base metals and $\operatorname{Var}\left(c_{t}\right)$ is the variance of the extracted cyclical component. The lower the $R^{2}$ the less the significance of time trend component. This measure is identical to the coefficient of determination in linear and quadratic trendlines and could be interpreted similarly for HP and BK filters. As the flexibility of filters increases from linear to the BK filters the significance of the trend component increases (Table 3) and consequently the variance or standard deviation of the cyclical component decreases.

Table 3: The importance of trend component in different methods

\begin{tabular}{lcccc}
\hline & Linear & Quadratic & HP & BK \\
\hline Aluminum & 0.38 & 0.40 & 0.66 & 0.90 \\
\hline Copper & 0.00 & 0.52 & 0.72 & 0.91 \\
\hline Nickel & 0.00 & 0.19 & 0.60 & 0.90 \\
\hline Lead & 0.03 & 0.34 & 0.74 & 0.92 \\
\hline Tin & 0.30 & 0.40 & 0.92 & 0.97 \\
\hline Zinc & 0.07 & 0.15 & 0.52 & 0.83 \\
\hline
\end{tabular}

Table 3 shows that linear trendline is a poor fit in the majority of base metals. There is an exception for aluminum and tin. Aluminum price is trend stationary, so the linear trendline is a good estimation of the time trend component. Figure 4 shows that the 43 
growth rate or the long-term trend in aluminum price is negative. The same behavior is apparent in the result of quadratic, the HP and the BK filters. This implies a downward trend in aluminum price which is consistent with Prebisch-Sanger hypothesis. Although a linear trendline gives a relatively good fit to the tin price, the same interpretation is not appropriate. There is a significant change from linear and quadratic trendlines to the time trend component of the HP and the BK filters and the growth component of HP filter looks more like a super cycle between 1970 and 2013 than resembling a downward trend. The copper price follows a U-shape trend over 1970 to 2013 . The $\mathrm{R}^{2}$ of the quadratic trendline is relatively high and the same pattern is apparent in the time trend component of the HP and the BK filters. Figure 5 illustrates a U-shape pattern in copper price. In order to identify the time trend components of nickel (figure 6) and zinc (figure 9), the linear and quadratic trendlines are not helpful. This is mainly due to the insignificance of linear time coefficient of nickel and low $\mathrm{R}^{2}$ of both linear and quadratic trendlines in nickel and zinc prices. The growth component of HP filter does not help in this case.

\section{Discussion}

Once trendlines have been fitted to the base metal prices, they could be considered as the time trend component of the series. All trendlines including linear, quadratic, the growth component of the HP filter and the moving average of the BK filter that captures the long-term variations in the base metal prices should be removed from the 
series to provide the data for analyzing the cyclical component. The removal of time trend component is simply done by subtracting the trend line from observed prices. In other words, the cyclical component of a series using a detrending method is the residuals of regressing a trendline on the real prices of base metals. The output of applying a filter to the real prices of base metals is considered as the cyclical component using filtering method.

It is worth mentioning that the choice of trend component has some effect on the cyclical component. Removing the trend component may affect the phases by shifting them forward or backward and consequently the overall cycle could be overstated or understated. This section reviews and compares the properties of detrending or filtering methods. In this regard, each deterending method is compared with other methods according to the ability of the detrending method to remove the unit root in the series (Baxter and King 1999). The goodness of the method is tested by testing the presence of unit roots in the cyclical components. The similarity of extracted cyclical components in each metal is also tested by comparing the correlation coefficients between the cyclical components extracted by different methods. Furthermore, the identified cycles are depicted and the statistics of cycles are compared in each metal using different detrending methods. 


\subsection{General properties of detrending methods}

The linear trend is the simplest and most used method to identify the time trend component of time series. This method is easy to apply and does not shift the cycles or alter the frequency of phases, but it may not be able to remove unit roots from the series. This method is applicable to stationary series, but in the existence of a unit root or intense variation in the series, a linear trendline is not a good fit and in many cases the coefficient of the time variable is not statistically significant. An alternative to the linear trend is a quadratic trendline. Detrended series by removing a quadratic trendline are also not subject to cycle shifts or cycle frequency alteration. The coefficient of determination and significance of time variables determines the goodness of fit and should be taken into consideration in order to select a detrending method. The HP filter has been used in this study to capture the time trend component of base metal prices and identify the cyclical component. The HP filter has the ability to remove the unit root by using a two-sided moving average to smooth the series. This filter does not shift the cycles, but changes the frequency of cycles. The BK filter removes a unit root by a centered two-sided moving average. The BK filter truncates the cyclical component by the lag length of $2 K$. Although the performance of the BK filter increases by increasing $K$, the loss of observation is a disadvantage. If a $\mathrm{BK}$ filter is used as a band pass filter, it changes the frequency of the cycles. These properties are reviewed further in this section. 


\subsection{Removing the unit root}

One of the properties of a good detrending or filtering method is to remove the unit root from the series. This is an important feature in non-stationary series. The residuals of detrending or filtering method are required to be stationary, because with the existence of a unit root in a series the behavior of the series depends on the time component and decreases the applicability of spectral analysis (Baxter and King 1999). In order to test the stationarity of the decomposed cyclical components of filtering, the ADF test is applied. Table 4 presents the t-statistics of ADF test on the residuals of detrending methods.

Table 4: Unit root test of the cyclical components of different methods

\begin{tabular}{lcccc}
\hline & Linear & Quadratic & HP & BK \\
\hline Aluminum & -4.01 & -4.18 & -5.87 & -6.26 \\
\hline Copper & -2.81 & -4.60 & -6.34 & -6.98 \\
\hline Nickel & -3.07 & -3.34 & -6.57 & -7.88 \\
\hline Lead & -1.47 & -2.95 & -5.16 & -7.53 \\
\hline Tin & -1.82 & -2.53 & -6.26 & -7.75 \\
\hline Zinc & -4.98 & -5.38 & -6.86 & -7.17 \\
\hline
\end{tabular}

$\dagger$ MacKinnon one-sided critical values: 1\% (-2.56), 5\% (-1.94), 10\% (-1.61)

The results show the residuals of linear detrending for aluminum, copper, nickel and zinc are stationary at 5\% level of significance, so this method is applicable to these metals. This implies that application of linear detrending to lead and tin is not appropriate. 


\subsection{Correlations between the cyclical components}

The difference between correlation coefficients of the cyclical components of base

metal prices, when detrended by linear, quadratic, HP and BK filtering methods is a measure of the difference between detrending methods. In tables 5-10 the correlation coefficients of cyclical component of base metal prices are displayed.

Table 5: Correlation of the cyclical components of aluminum price using different methods

\begin{tabular}{lcccc}
\hline & Linear & Quadratic & HP & BK \\
\hline Linear & 1.00 & & & \\
\hline Quadratic & 0.99 & 1.00 & & \\
\hline HP & 0.86 & 0.88 & 1.00 & \\
\hline BK & 0.67 & 0.68 & 0.83 & 1.00 \\
\hline
\end{tabular}

Table 6: Correlation of the cyclical components of copper price using different methods

\begin{tabular}{lcccc}
\hline & Linear & Quadratic & HP & BK \\
\hline Linear & 1.00 & & & \\
\hline Quadratic & 0.77 & 1.00 & & \\
\hline HP & 0.63 & 0.85 & 1.00 & \\
\hline BK & 0.50 & 0.67 & 0.83 & 1.00 \\
\hline
\end{tabular}


Table 7: Correlation of the cyclical components of nickel price using different methods

\begin{tabular}{lcccc}
\hline & Linear & Quadratic & HP & BK \\
\hline Linear & 1.00 & & & \\
\hline Quadratic & 0.94 & 1.00 & & \\
\hline HP & 0.74 & 0.84 & 1.00 & \\
\hline BK & 0.59 & 0.65 & 0.84 & 1.00 \\
\hline
\end{tabular}

Table 8: Correlation of the cyclical components of lead price using different methods

\begin{tabular}{lcccc}
\hline & Linear & Quadratic & HP & BK \\
\hline Linear & 1.00 & & & \\
\hline Quadratic & 0.88 & 1.00 & & \\
\hline HP & 0.64 & 0.78 & 1.00 & \\
\hline BK & 0.49 & 0.60 & 0.83 & 1.00 \\
\hline
\end{tabular}

Table 9: Correlation of the cyclical components of tin price using different methods

\begin{tabular}{lcccc}
\hline & Linear & Quadratic & HP & BK \\
\hline Linear & 1.00 & & & \\
\hline Quadratic & 0.95 & 1.00 & & \\
\hline HP & 0.49 & 0.53 & 1.00 & \\
\hline BK & 0.38 & 0.40 & 0.84 & 1.00 \\
\hline
\end{tabular}

Table 10: Correlation of the cyclical components of zinc price using different methods

\begin{tabular}{lcccc}
\hline & Linear & Quadratic & HP & BK \\
\hline Linear & 1.00 & & & \\
\hline Quadratic & 0.97 & 1.00 & & \\
\hline HP & 0.85 & 0.91 & 1.00 & \\
\hline BK & 0.66 & 0.71 & 0.83 & 1.00 \\
\hline
\end{tabular}


The correlation coefficients between the cyclical components extracted by linear and quadratic trends are generally high $(>0.94)$ except for the copper price $(0.77)$. This shows that the cyclical behavior of real prices detrended by linear methods are very similar. The correlations between the residuals of filtering methods are also high $(>0.83)$. This is mainly related to similarities of the HP with BK filters. The correlation between linear detrending and BK filtering is relatively lower than the correlation between linear detrending and HP filtering or quadratic detrending. This feature shows the similarity of cyclical components is decreasing as the difference between flexibility of methods increases.

\subsection{Differences between the identified cycles in base metal prices}

The focus of this part of research is to identify cycles from the cyclical components of base metal prices. The outputs of detrended series provide the data for further analysis including identification of price cycles. There are several algorithms to identify the cycles in economic data. One of the beginning methods in this regard is attributed to Burns and Mitchell (1946). Their procedure in cycles and turning points identification has been used extensively and became the NBER procedure in identifying business cycles. Bry and Boschan (1971) developed a procedure to search for the expansion and contraction in a series. In their terminology a cycle consists of an expansion phase from a previous trough to a peak and a contraction is defined as the time between a peak to the next trough. In other words, a full cycle goes from a 
trough to the next trough or from a peak to the next peak (Bry and Boschan 1971). Another seminal work in detecting cycles in economic time series is attributed to Harding and Pagan (2002). In order to identify the cycles the Harding and Pagan (2002) cycle identification method is applied to the cyclical component of base metal prices. 

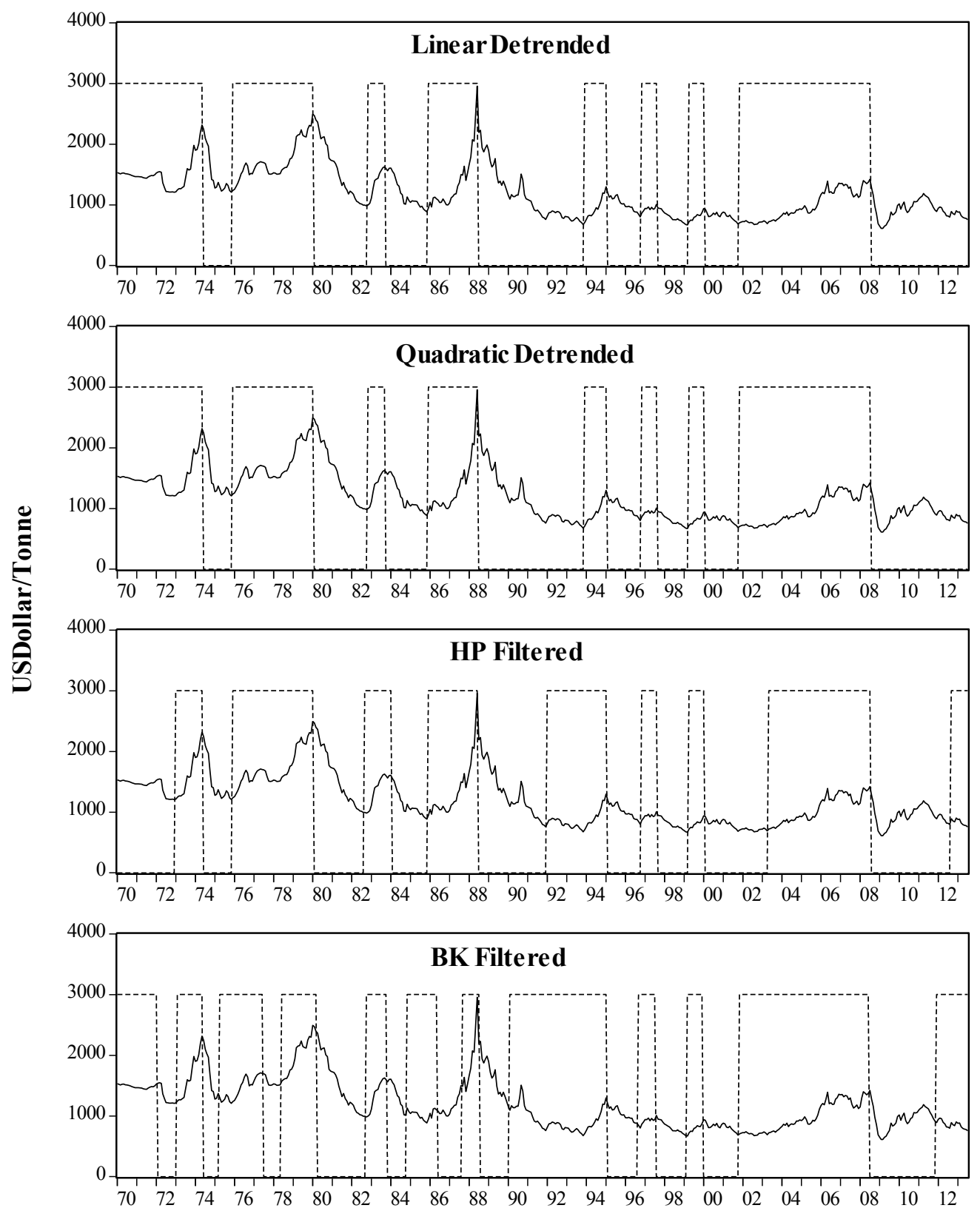

Figure 10: Real aluminum price and expansion phases 

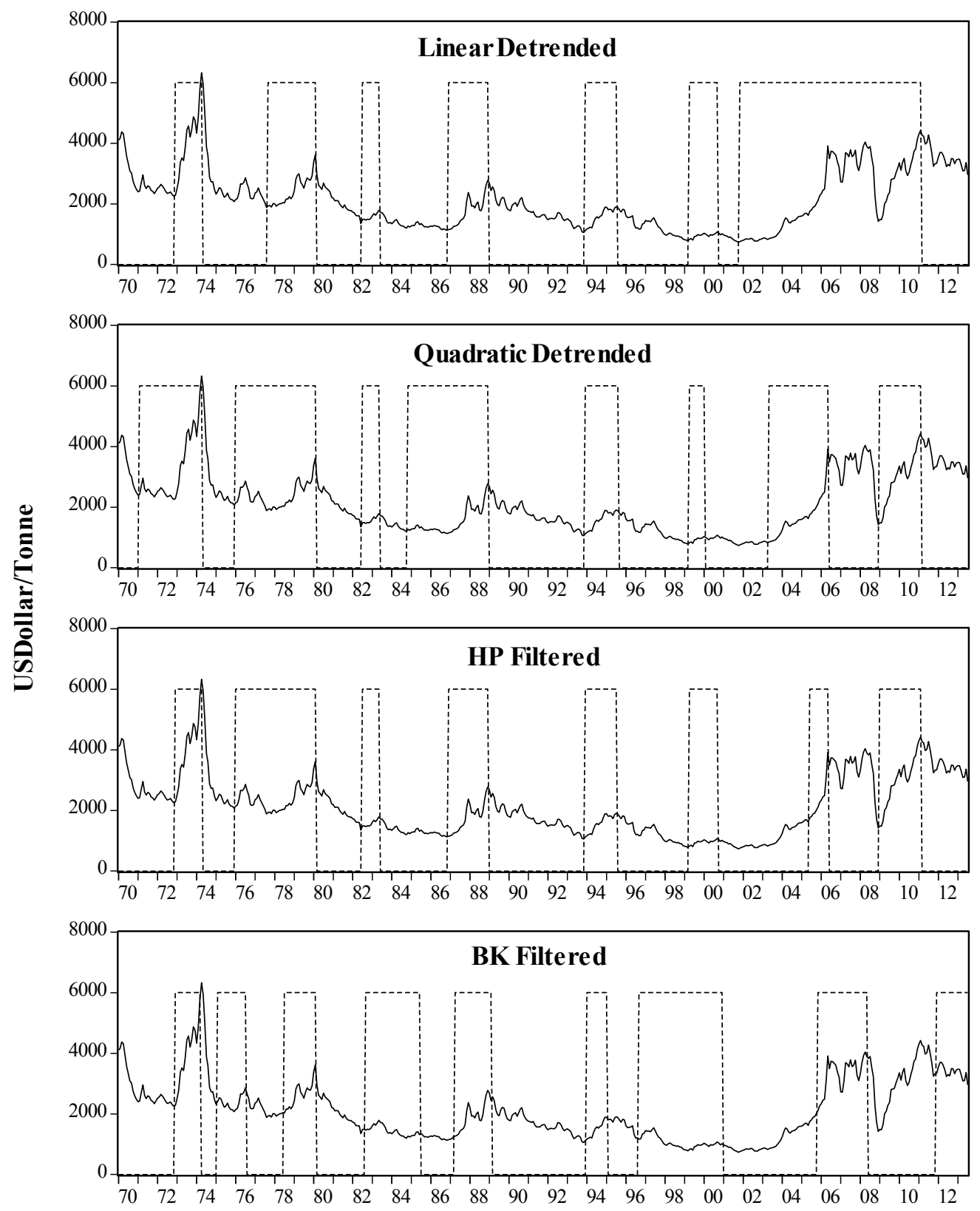

Figure 11: Real copper price and expansion phases 

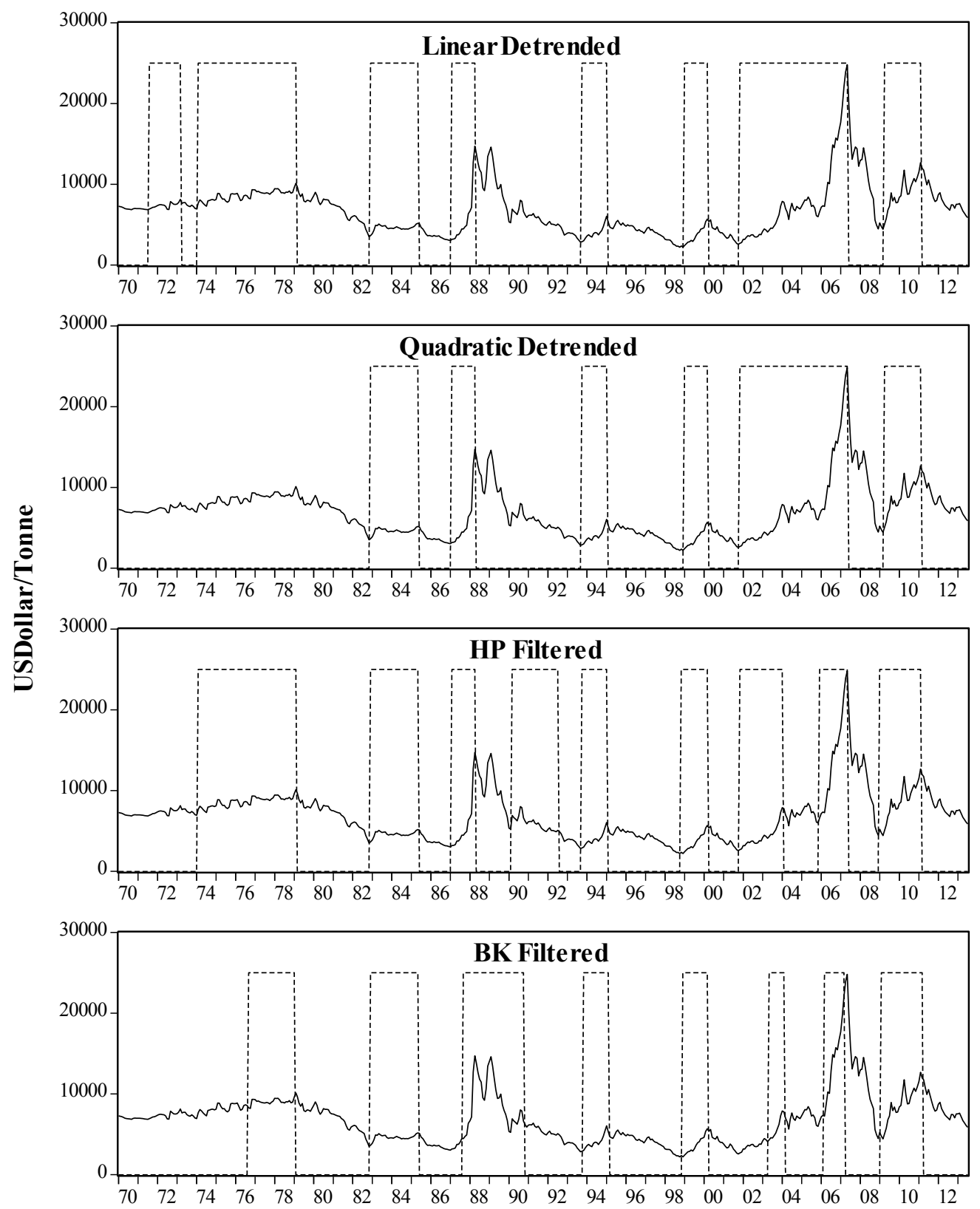

Figure 12: Real nickel price and expansion phases 

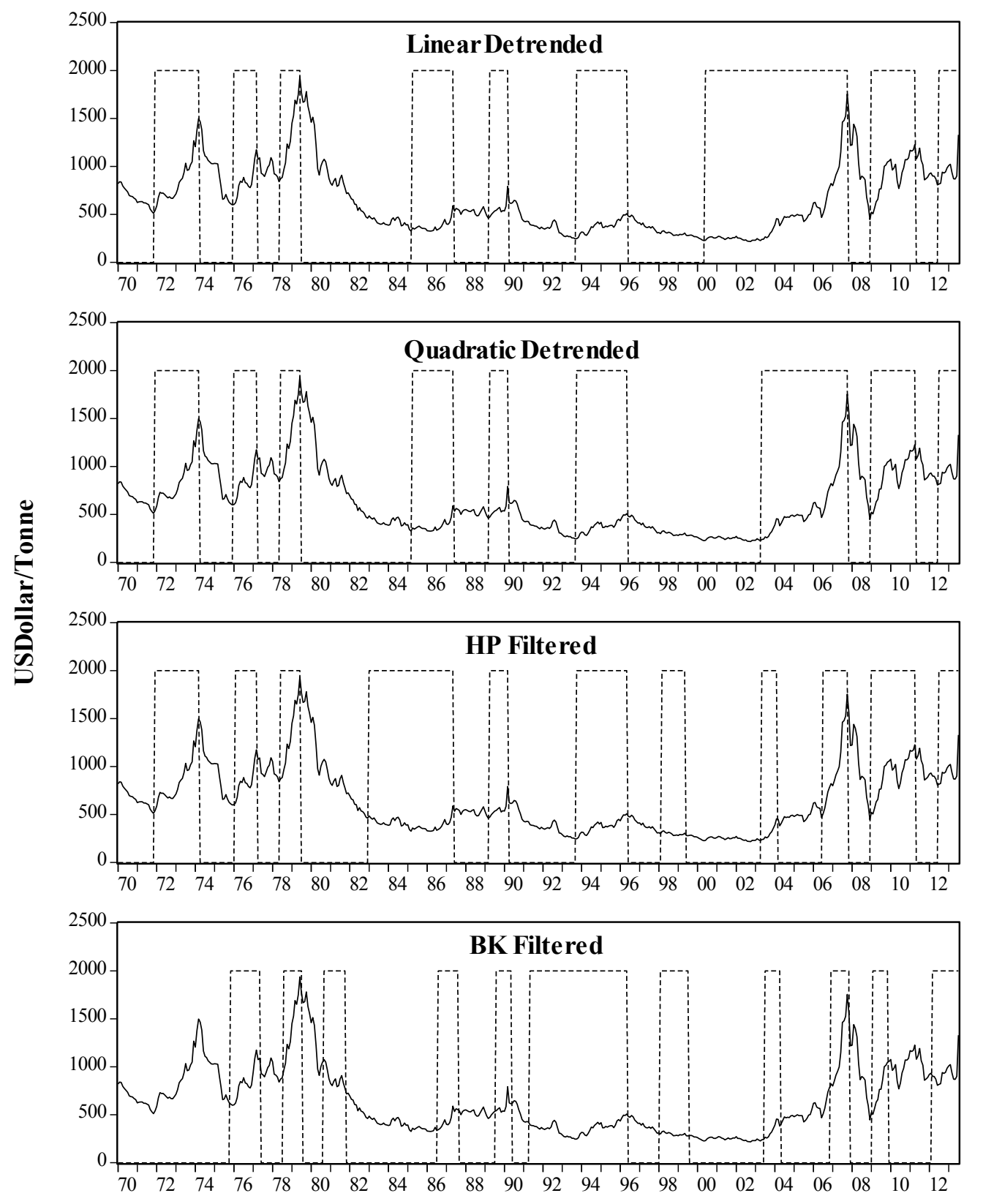

Figure 13: Real lead price and expansion phases 

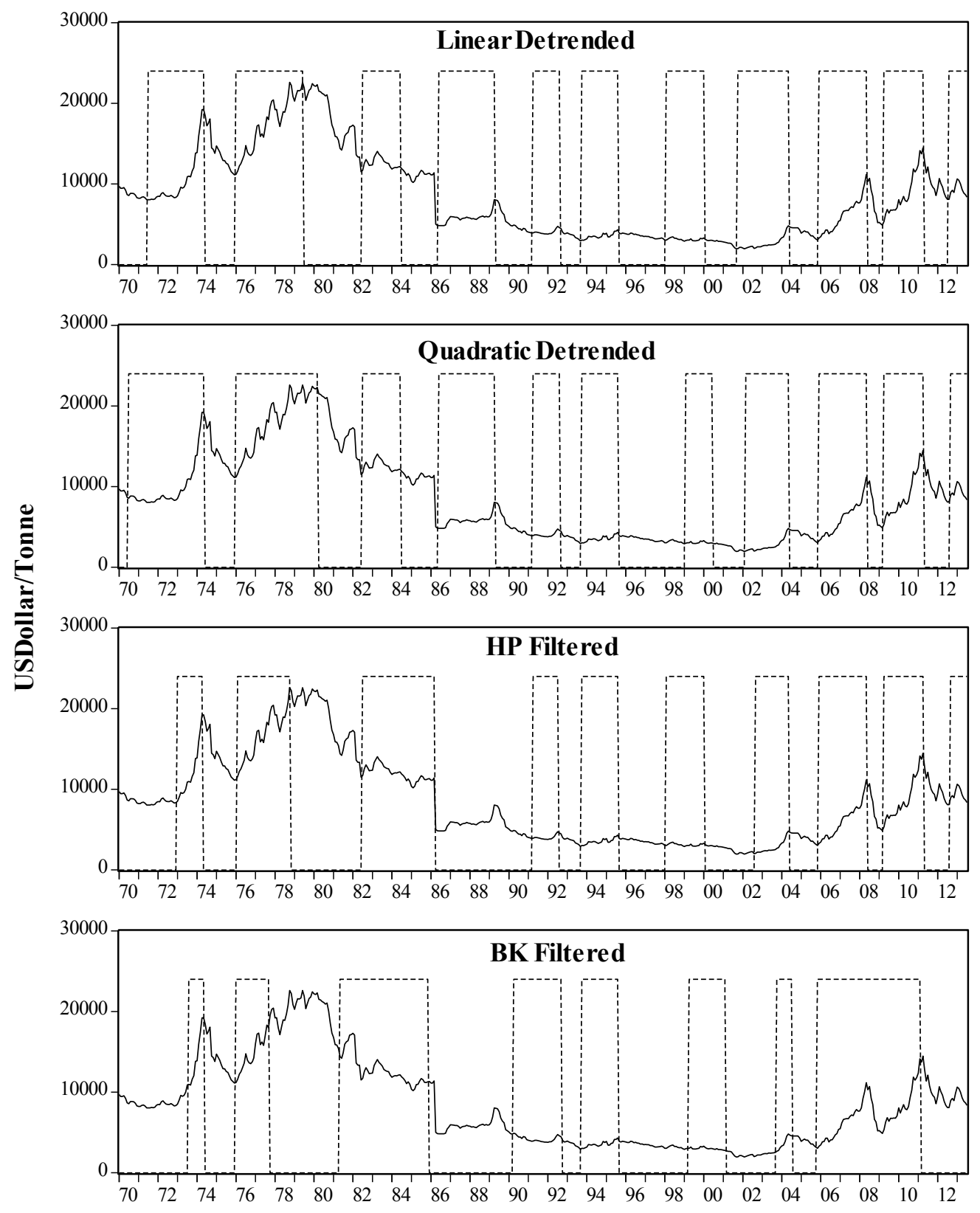

Figure 14: Real tin price and expansion phases 

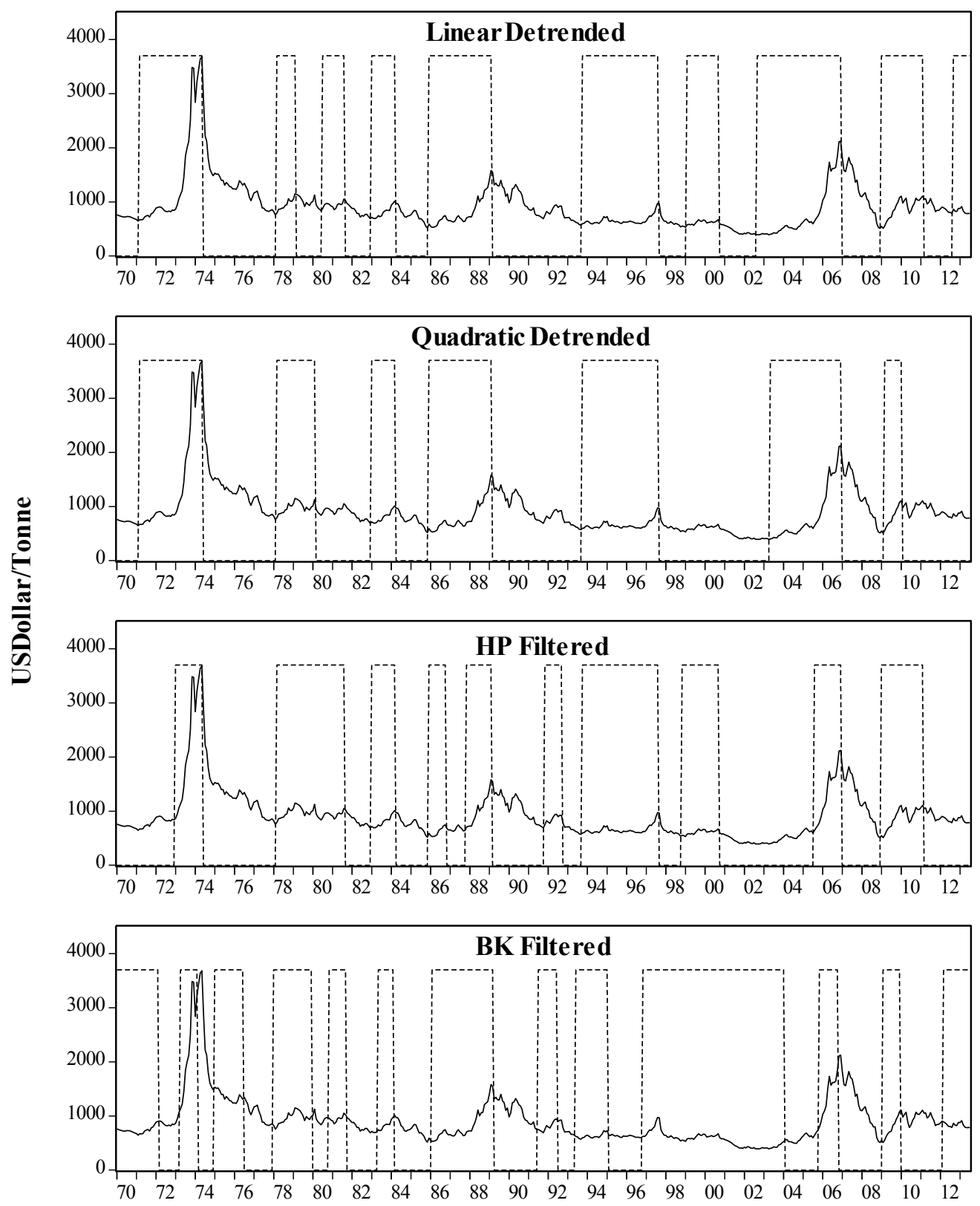

Figure 15: Real zinc price and expansion phases 
Figures 10-15 illustrate in graphical form, the identified cycles including expansion and contraction phases with the real price of base metals. The main reason for missing phases and turning points in the beginning and end of the graphs is related to the loss of data from smoothing. The expansion and contraction phases and their associated turning points are detected using the Harding and Pagan (2002) procedure. In this method, the relative maximum and minimums are detected in the series and assigned as peaks and troughs following these steps:

1. The output of a filter or the residuals of detrending method provide the data for identification of cycles in the base metal prices. Linear and quadratic detrending methods, and Hodrick and Prescott (1997) filter and Baxter and King (1999) filters are applied to monthly real base metal prices from 1970:1 to 2013:7 to reveal the cyclical components of base metal prices.

2. A 12 month window is applied on the cyclical component of base metal prices to identify relative maximums such that $\left(p_{t-12}, p_{t-11}, \ldots . p_{t-1}\right)<p_{t}$ and $p_{t}>$ $\left(p_{t+1}, p_{t+2}, \ldots . p_{t+12}\right)$ and assign them as peaks in the series of prices. Troughs are located in the series following the same procedure such that $\left(p_{t-12}, p_{t-11}, \ldots . p_{t-1}\right)>p_{t}$ and $p_{t}<\left(p_{t+1}, p_{t+2}, \ldots . p_{t+12}\right)$.

3. Peaks and troughs should alternate successively. If more than one maximums (minimums) are detected in the series, the highest (lowest) would be the relative peak (trough) in the cycle and the lower will be suppressed to zero. 
4. A binary series is created to show the expansion and contraction months by 1 and 0 , respectively.

In these figures peaks and troughs appear respectively at the right and left ends of expansion phases. A full cycle can be measured from a peak to the next peak or a trough to the next trough. Visual inspection of the graphs of each metal shows the difference between the identified cycles and associated turning points. Since the same procedure has been applied to the cyclical components, the difference between detected cycles stemmed from the difference between the cyclical components. This shows detected cycles have been affected by the choice of the detrending or filtering method which has been applied to a series.

Table 11: Duration of phases in aluminum price using different methods

\begin{tabular}{lccccccccc}
\hline & \multicolumn{4}{c}{ Expansion } & \multicolumn{3}{c}{ Contraction } \\
\hline Cycle & Min & Max & Mean & Stdev & Min & Max & Mean & Stdev \\
\hline Quadratic & 8 & 10 & 52 & 21.0 & 14.5 & 10 & 65 & 27.9 & 16.7 \\
\hline HP & 8 & 10 & 52 & 25.4 & 19.0 & 18 & 65 & 29.0 & 16.7 \\
\hline BK & 11 & 10 & 63 & 29.4 & 19.5 & 18 & 49 & 30.1 & 11.9 \\
\hline
\end{tabular}

Table 12: Duration of phases in copper price using different methods

\begin{tabular}{lccccccccc}
\hline & \multicolumn{4}{c}{ Expansion } & \multicolumn{3}{c}{ Contraction } \\
\hline & Cycle & Min & Max & Mean & Stdev & Min & Max & Mean & Stdev \\
\hline Linear & 6 & 11 & 30 & 20.2 & 6.62 & 13 & 59 & 37.7 & 15.6 \\
\hline Quadratic & 7 & 10 & 50 & 31 & 17.2 & 17 & 59 & 34 & 14.6 \\
\hline HP & 7 & 11 & 50 & 21.9 & 13.3 & 20 & 59 & 40 & 14.5 \\
\hline BK & 8 & 13 & 52 & 25.9 & 12.8 & 10 & 58 & 32.6 & 18.2 \\
\hline
\end{tabular}


Table 13: Duration of phases in nickel price using different methods

\begin{tabular}{lccccccccc}
\hline & \multicolumn{4}{c}{ Expansion } & \multicolumn{3}{c}{ Contraction } \\
\hline & Cycle & Min & Max & Mean & Stdev & Min & Max & Mean & Stdev \\
\hline Linear & 7 & 15 & 67 & 32.0 & 22.5 & 10 & 65 & 32.6 & 19.9 \\
\hline Quadratic & 7 & 15 & 67 & 28.6 & 22.4 & 19 & 65 & 34.6 & 20.6 \\
\hline HP & 8 & 15 & 61 & 26.6 & 15.2 & 14 & 45 & 25.8 & 12.1 \\
\hline BK & 7 & 10 & 38 & 21.7 & 10.8 & 22 & 46 & 34.0 & 9.8 \\
\hline
\end{tabular}

Table 14: Duration of phases in lead price using different methods

\begin{tabular}{lccccccccc}
\hline & \multicolumn{4}{c}{ Expansion } & \multicolumn{3}{c}{ Contraction } \\
\hline & Cycle & Min & Max & Mean & Stdev & Min & Max & Mean & Stdev \\
\hline Linear & 8 & 12 & 89 & 30.4 & 24.9 & 14 & 69 & 30.5 & 20.4 \\
\hline Quadratic & 8 & 12 & 54 & 26.0 & 13.7 & 14 & 83 & 34.9 & 27.2 \\
\hline HP & 9 & 10 & 53 & 21.4 & 14.0 & 14 & 47 & 27.1 & 13.3 \\
\hline BK & 10 & 10 & 61 & 17.9 & 15.5 & 11 & 57 & 25.7 & 15.5 \\
\hline
\end{tabular}

Table 15: Duration of phases in tin price using different methods

\begin{tabular}{lccccccccc}
\hline & \multicolumn{4}{c}{ Expansion } & \multicolumn{3}{c}{ Contraction } \\
\hline & Cycle & Min & Max & Mean & Stdev & Min & Max & Mean & Stdev \\
\hline Linear & 10 & 16 & 42 & 28.6 & 7.6 & 10 & 36 & 20.7 & 7.6 \\
\hline Quadratic & 10 & 12 & 51 & 28.3 & 11.0 & 10 & 41 & 21.1 & 8.5 \\
\hline HP & 10 & 16 & 45 & 25.9 & 9.1 & 10 & 60 & 27.0 & 16.2 \\
\hline BK & 7 & 10 & 55 & 24.6 & 15.3 & 12 & 52 & 30.7 & 15.8 \\
\hline
\end{tabular}

Table 16: Duration of phases in zinc price using different methods

\begin{tabular}{lccccccccc}
\hline & \multicolumn{4}{c}{ Expansion } & \multicolumn{3}{c}{ Contraction } \\
\hline & Cycle & Min & Max & Mean & Stdev & Min & Max & Mean & Stdev \\
\hline Linear & 9 & 12 & 52 & 29.3 & 15.2 & 16 & 55 & 26.0 & 14.1 \\
\hline Quadratic & 6 & 15 & 47 & 34.7 & 12.5 & 20 & 68 & 41.3 & 18.2 \\
\hline HP & 9 & 11 & 47 & 22.1 & 13.2 & 12 & 58 & 25.9 & 16.2 \\
\hline BK & 11 & 10 & 87 & 22.2 & 23.0 & 10 & 27 & 20.3 & 5.7 \\
\hline
\end{tabular}


Tables 11 to 16 show the behavior of the cyclical component of base metal prices. These tables include the minimum, maximum, the average and standard deviation of expansion and contraction phases in base metal prices extracted by different detrending methods and filters. These tables also show that the number of detected cycles in each metal price varies by the detrending method.

\section{Conclusions}

Analyzing the behavior of economic time series is a complicated task. One of the main reason for this is the ever changing trend and many frequent fluctuations around it. Decomposition analysis of economic time series is the process of extracting a low frequency component known as the time trend and a higher frequency component which is known as the cyclical component. There are many different methods and techniques for decomposing time series into its components. They differ from each other mainly in the way they identify the trend, and how they handle the cyclical component. In this regard, one has to make assumptions which influence the results and analysis. This research is a study of the long-term trend and cyclical fluctuations of the real price of base metals. The incentive for choosing time series analysis to examine the behavior of base metal prices stems from the existence of several different theories about the mineral prices. With the lack of a robust theory about commodity price behavior, any effort to model prices leads to different and in some cases opposing findings. 
This research is one among many studies which have been devoted to analyze, model and forecast commodity prices. Generally, identification of the time trend component and examination of the long-term behavior is getting more complicated as the goodness of fit increases in base metal prices. A linear trendline gives a poor fit, but interpreting the behavior of the price is apparently easier than an almost perfect fit by the application of HP filter or BK filters. As mentioned before, there is a penalty for better smoothness of the cyclical component; the smoother the time trend, the more variation in the cyclical component. It is worth mentioning that the BK trend component is a very good fit to the data series and could hardly be considered as the long-term trend component. Moreover, the loss of data points at the end of the sample, prevents identification of the most recent behavior in a series. Therefore, a relatively good fit by regressing a linear or quadratic trend is more favorable than better fits accomplished by applying filters to a series if the time coefficients are statistically significant. Less impact on the cyclical component, using the full sample, and the easier interpretation of long-term behavior are the advantages of linear and quadratic trendlines over the more flexible filtering methods.

The long-term trend of base metal prices reviewed in this research varies from linear and quadratic deterministic trends to flexible HP and BK filters. In this regard, the main finding is that it is difficult to determine any particular trend line in base metal prices, however, quadratic trendlines give a good fit comparing to other filtering methods in copper, lead, tin and zinc prices, which is in agreement with Slade's 
model. On the other hand, a negative linear deterministic trend, describes the behavior of aluminum price well, which is consistent with Prebisch-Singer thesis. Generally, using HP filtering of base metal prices gives a very good fit and the trend component has enough flexibility to capture the variability of prices. Moreover, if the smoothness parameter is determined appropriately, the trend component would explain the longterm behavior of price more accurately.

The other finding of this research is related to the cyclical component of prices. The choice of filtering or detrending methods is influential on the cyclical component of prices. In this regard, the characteristics of a data series such as volatility should be taken into consideration in adjusting the parameters of the filter to be applied. Moreover, the cycle identification procedure assumptions including the minimum phase and cycle duration, affect the expansion and contraction phases and their associated turning points. Given the same procedure to detect the cycles in base metal prices, the HP filter has some favorable characteristics over the other detrending and filtering methods. The time growth or time trend component of the HP filter captures low frequency fluctuations, removes unit roots and does not have a significant impact on the cyclical component. The smoothing parameter of the HP filter allows the user to adjust it to a desired level depending on the importance of the time trend component or cyclical component. This feature of the HP filter is very desirable as identification of cycles is highly dependent on the filtering method, its properties and adjustments. 
Although the effects of different detrending and filtering methods on trend identification and cyclical components were reviewed in this thesis, this is by no means a complete study. First, other deterending approaches such as fitting logarithmic and higher order polynomial trendlines, and other filtering methods such as Christiano-Fitzgerald and Butterworth filters were not studied in this research. Second, there is no variation in the parameters of applied filters in this study. For example, the smoothing parameter of the HP filter was set to 129,600 , and for the BK filter the truncation lag of $K=20$ and low and high cycle periods limits of 12 and 40 months were reviewed in this study, which are the most commonly values based on other studies and behavior of base metal prices. Other values will give different results which have not been considered in this research. Third, the data sample in this study is comprised of only base metal prices which is a small sample in the area of primary commodities. Fourth, long-term trend identification suffers from the time span of this study. Fifth, this study does not make any conclusion about the characteristics of an optimal detrending or filtering methods. In other words, no benchmark or ideal method was introduced in this study. Consequently, identification of the best time trend component which explains the long-term behavior and will result in the most accurate cycles are very subjective and remain as other limitations of this study. These limitations could be overcome in future research. 


\section{References}

Barnett, H. J. and C. Morse (1963). "Scarcity and growth." Scarcity and growth.

Baxter, M. and R. G. King (1999). "Measuring business cycles: approximate bandpass filters for economic time series." Review of economics and statistics 81(4): 575 593.

Blanchard, O. J., W. D. Nordhaus and E. S. Phelps (1997). "The medium run." Brookings Papers on Economic Activity 1997(2): 89-158.

Bry, G. and C. Boschan (1971). Front matter to" Cyclical Analysis of Time Series:

Selected Procedures and Computer Programs". Cyclical Analysis of Time Series: Selected Procedures and Computer Programs, UMI: -13--12.

Burns, A. F. and W. C. Mitchell (1946). "Measuring business cycles." NBER Books.

Canova, F. (1998). "Detrending and business cycle facts." Journal of monetary economics 41(3): 475-512.

Christiano, L. J. and T. J. Fitzgerald (2003). "The Band Pass Filter*." International Economic Review 44(2): 435-465. 
Cuddington, J. T. (1992). "Long-run trends in 26 primary commodity prices: A disaggregated look at the Prebisch-Singer hypothesis." Journal of Development Economics 39(2): 207-227.

Cuddington, J. T. and G. Nülle (2013). "Variable Long-Term Trends in Mineral Prices: The Ongoing Tug-of-War between Exploration, Depletion, and Technological Change." Journal of International Money and Finance.

Davutyan, N. and M. C. Roberts (1994). "Cyclicality in metal prices." Resources Policy 20(1): 49-57.

Dickey, D. A. and W. A. Fuller (1981). "Likelihood ratio statistics for autoregressive time series with a unit root." Econometrica: Journal of the Econometric Society: 10571072.

Harding, D. and A. Pagan (2002). "Dissecting the cycle: a methodological investigation." Journal of monetary economics 49(2): 365-381.

Hodrick, R. J. and E. C. Prescott (1997). "Postwar US business cycles: an empirical investigation." Journal of Money, credit, and Banking: 1-16.

Hotelling, H. (1931). "The economics of exhaustible resources." The Journal of Political Economy 39(2): 137-175. 
Krugman, P. R., K. M. Dominquez and K. Rogoff (1998). "It's baaack: Japan's slump and the return of the liquidity trap." Brookings Papers on Economic Activity 1998(2): 137-205.

Labys, W. C. (2006). Modeling and forecasting primary commodity prices, Ashgate Publishing.

Labys, W. C., J. Lesourd and D. Badillo (1998). "The existence of metal price cycles1." Resources policy 24(3): 147-155.

Lebow, D. E. and J. B. Rudd (2006). Inflation measurement, Divisions of Research $\&$ Statistics and Monetary Affairs, Federal Reserve Board.

Lewis, W. A. (1954). "Economic development with unlimited supplies of labour." The manchester school 22(2): 139-191.

Manthy, R. S. and N. Potter (1978). Natural resource commodities: a century of statistics: prices, output, consumption, foreign trade, and employment in the United States, 1870-1973, Published for Resources for the Future by the Johns Hopkins University Press.

Potter, N. and F. T. Christy (1962). Trends in natural resource commodities: Statistics of prices, output, consumption, foreign trade, and employment in the United States, 1870-1957, Published for Resources for the Future by Johns Hopkins Press. 
Radetzki, M. (2008). A handbook of primary commodities in the global economy, Taylor \& Francis.

Ravn, M. O. and H. Uhlig (2002). "On adjusting the Hodrick-Prescott filter for the frequency of observations." Review of Economics and Statistics 84(2): 371-376.

Roberts, M. C. (2009). "Duration and characteristics of metal price cycles." Resources Policy 34(3): 87-102.

Slade, M. E. (1982). "Trends in natural-resource commodity prices: an analysis of the time domain." Journal of Environmental Economics and Management 9(2): 122-137.

Solow, R. M. (2000). "Toward a macroeconomics of the medium run." The Journal of Economic Perspectives 14(1): 151-158.

Tilton, J. (2003). On borrowed time?: Assessing the threat of mineral depletion, RFF Press.

Warren, G. F. and F. A. Pearson (1933). Prices, Wiley.

Watkins, C. and M. McAleer (2004). "Econometric modelling of non-ferrous metal prices." Journal of Economic Surveys 18(5): 651-701. 